Elsevier required licence: (C) $<2015>$. This manuscript version is made available under the CC-BY-NC-ND 4.0 license http://creativecommons.org/licenses/by-nc-nd/4.0/ 


\title{
Management control systems across different modes of innovation: Implications for firm performance
}

\author{
David S. Bedford \\ University of Technology, Sydney \\ PO Box 123 \\ Broadway, NSW 2007 \\ Australia \\ Email: David.Bedford@uts.edu.au \\ Phone: +61295143638 \\ Fax: +61295143669
}

\begin{abstract}
This study examines the use of management control systems (MCS) across different modes of innovation and the effects on firm performance. In particular, the study draws on Simons' levers of control framework to investigate how top managers attempt to simultaneously balance exploration and exploitation, which place contradictory requirements on firms. Using data collected from a survey of top managers in 400 firms the study demonstrates that the patterns of use and interdependencies among control levers associated with enhanced performance differ depending on the mode of innovation. The findings show that control levers are independently associated with enhanced performance in firms that specialize in either exploration or exploitation, suggesting that levers operate as supplementary rather than complementary controls in these contexts. However, in ambidexterity firms, diagnostic and interactive levers are shown to have interdependent effects on performance. Furthermore, some evidence suggests that both the combined and balanced use of these levers contributes to generating dynamic tension necessary for managing contradictory innovation modes.
\end{abstract}

Keywords: management control systems; levers of control; dynamic tension; innovation; exploration; exploitation; ambidexterity; survey.

\section{Acknowledgements}

I would like to thank participants at the European Accounting Association meeting, Ljubljana, 2012, and the Manufacturing Accounting Research in Helsinki, 2012, and Josep Bisbe, Anna Loyeung, Ricardo Malagueño and Prabhu Sivabalan for their comments and suggestions. I am also grateful for the financial assistance and support provided by CPA Australia in this research project. 


\section{Introduction}

An emerging stream of research has revealed how management control systems (MCS) can play a central role in the management of innovation. ${ }^{1}$ Once considered to be detrimental to innovative efforts (Amabile, 1988; Damanpour, 1991), there is now growing consensus that formal controls, when activated in an enabling, facilitative and interactive fashion, increase the capacity of an organization to derive benefits from innovation (Bisbe and Otley, 2004; Jørgensen and Messner, 2009). However, most prior systematic investigations have considered only variations in the emphasis on innovation rather than the characteristics of innovation. As such, it is unclear as to whether the same control patterns are equally effective across different innovation types, or how MCS are employed when pursuing multiple and potentially contradictory innovation modes. As Davila et al. (2009, p. 284) note:

Innovation is not a monolithic phenomenon but various processes that coexist in parallel, each one requiring different types of control systems. Yet, we know little about how management control systems vary across variations of these processes, how they are designed, how they are used, how they interact $[\ldots]$

One common distinction in the innovation literature concerns the allocation of attention and resources between exploitation and exploration. Exploitation entails "refinement and extension of existing competencies" whereas exploration requires "experimentation with new alternatives" (March, 1991, p. 85). As the structures and routines associated with exploitation are fundamentally different to those necessary for exploration, firms will often specialize (Gupta et al., 2006). Some, however, attempt to pursue exploitation and exploration simultaneously. Managing the competing tensions and inconsistencies imposed by these contradictory innovation paths is signified by the term ambidexterity (Andriopoulos and Lewis, 2009; Lubatkin et al., 2006). While a significant body of research has documented the environmental, structural and behavioral antecedents of exploration, exploitation and ambidexterity (Jansen et al., 2006; Raisch and Birkinshaw, 2008; Simsek, 2009), little consideration has been given to how top managers employ MCS in these different innovation contexts (see Cardinal, 2001, for an exception).

Furthermore, researchers have only just begun to investigate the design and use of MCS in firms that jointly pursue multiple and contradictory strategic objectives. This is an important concern as the literature generally contends that the success of firms facing highly dynamic and competitive environments is dependent on their ability to balance conflicting requirements (Gibson and

\footnotetext{
${ }^{1}$ Management control is defined as "formal, information-based routines and procedures managers use to maintain or alter patterns in organizational activities" (Simons, 1995, p. 5).
} 
Birkinshaw, 2004; Simsek, 2009). To date accounting studies have provided insight into how firms design performance measurement systems when emphasizing both low cost and differentiation strategies. Recent research by Lillis and van Veen-Dirks (2008) and Dekker et al. (2013) show that joint strategy (ambidexterity) firms have more complex systems that emphasize a wider diversity of measures, reflecting managerial demands to balance rather than to tradeoff competing priorities.

The current study extends these streams of research by investigating the patterns of MCS use by top managers for firms that either specialize in, or jointly pursue, exploration and exploitation. In this study, MCS are conceptualized in terms of Simons' $(1995,2000)$ levers of control (LOC) framework. The LOC framework is particularly appropriate for this study as it explicitly draws attention to the interplay of controls in managing organizational tensions (Mundy, 2010). Apart from Widener (2007) broad-sample research has been primarily concerned with the effects of interactive control (Abernethy and Brownell, 1999; Bisbe and Otley, 2004; Bisbe and Malagueño, 2009; Henri, 2006; Naranjo-Gil and Hartmann, 2007), limiting our understanding of how and when the full range of control levers are activated or combined and with what consequence. Recent field work has, however, been quite insightful in illustrating how the levers of control function as an interdependent system (Chenhall et al., 2010; Frow et al., 2010; Marginson, 2002; Mundy, 2010). Building on these insights, this study investigates both the individual and complementary effects of control levers on performance across different innovation modes. Additionally, this study empirically distinguishes between the combined and balanced use of control levers in generating dynamic tension (Simons, 1995). Although recent case studies have elaborated on how managers attempt to balance competing priorities through MCS (Cardinal et al., 2004; Jørgensen and Messner, 2009; Mundy, 2010), the effects of balance between control levers has not been formally tested.

The remainder of this study is organized as follows. The next section reviews the literature and develops hypotheses that associate the use of control levers with firm performance across different modes of innovation. Section 3 describes the research method followed by the presentation and discussion of results. The study concludes with an outline of the limitations of this study and directions for future research.

\section{Literature review and hypothesis development}

Exploitation and exploration represent fundamentally disparate modes of learning and innovation (March, 1991). Exploitation is encapsulated by terms such as "refinement, choice, production, efficiency, selection, implementation, execution" while exploration is indicative of "search, variation, risk taking, experimentation, play, flexibility, discovery, innovation" (March, 1991, p. 71). Exploitative activities are directed towards increasing the efficacy of the technical system by 
leveraging experiential learning gained through the repetition of routines. Through successive iterations the organization makes modifications to established processes to increase the proficiency and reliability of task performances. This process of incremental learning reinforces and deepens organizational capabilities along a given technological trajectory (Benner and Tushman, 2002; He and Wong, 2004). Conversely, explorative activities involve the search for new and emerging markets and the development of novel prototypes and path-breaking technologies. This requires organizations to pursue radical departures from prevailing competencies and learnt routines, and generate a tolerance for slack, persistent experimentation and improvisation of practices (Andriopoulos and Lewis, 2009; Jansen et al., 2006). ${ }^{2}$

Although March (1991) contends that exploitation and exploration place fundamentally incompatible requirements on an organization, he nevertheless maintains that both are essential for long-term survival. Firms investing in exploitation to the exclusion of exploration risk becoming trapped in suboptimal positions when environments shift, while those engaging in exploration at the expense of exploitation often fail to develop adequate competencies to capitalize on initial advantages (Holmqvist, 2004; Levinthal and March, 1993). Researchers investigating how balance can be achieved between exploitation and exploration present two main adaptive strategies: ambidexterity and punctuated equilibrium (Boumgarden et al., 2012; Gupta et al., 2006). Firms pursuing ambidexterity attempt to simultaneously manage the contradictory requirements of exploitation and exploration, while punctuated equilibrium refers to cycling between periods of specialization (Gupta et al., 2006). ${ }^{3}$ Situational conditions may also allow for or necessitate continued specialization. Stable and predictable environments and commoditized product markets tend to provide greater returns to organizations that effectively capitalize upon existing technologies, while highly dynamic and competitive conditions that are subject to rapid product obsolescence require continual emphasis on explorative activities to ensure survival (Benner and Tushman, 2003; Simsek, 2009). Specialization is also achievable through inter-organizational relationships when firms control complementary

\footnotetext{
${ }^{2}$ Exploration and exploitation are also closely related to other fundamental organizational tensions - e.g. incremental and radical innovation (Abernathy and Clark, 1985; Davila et al., 2009; Tushman and O'Reilly, 1996), local and distant knowledge search (Levinthal, 1997), single and double-loop learning (Argyris and Schön, 1978; Van de Ven, 1986), first-order and second-order competencies (Danneels, 2008), variationreducing and variation-increasing strategic processes (Adler et al., 1999; Burgelman, 1991, 2002) and environmental adaptation and adaptability (Weick, 1979).

${ }^{3}$ Prior literature describes two forms of ambidexterity, structural and contextual (Raisch et al., 2009). Structural ambidexterity refers to the partitioning of tasks between distinct subunits (Tushman and O'Reilly, 1996). In this approach the firm creates a dual structure where subunits develop unique competencies, cultures, systems and processes suited to the requirements of either exploration or exploitation (Duncan, 1976; Raisch et al., 2009). Contextual ambidexterity refers to the behavioural capacity of individuals to simultaneously address exploitation and exploration activities across the whole organization. This is achieved by "building a set of processes or systems that enable and encourages individuals to make their own judgments about how to divide their time between conflicting demands" (Gibson and Birkinshaw, 2004, p. 209). In both cases the literature recognizes that top management plays a pivotal role in achieving an effective balance and integration between competing strategic priorities (Simsek, 2009).
} 
resources - the explorative efforts of one firm feed into the exploitative capabilities of another (Gupta et al., 2006). These positions are represented in Fig. 1.

<Insert Fig. 1. about here>

The remainder of this section considers how MCS are expected to enhance firm performance for each innovation mode by drawing on the LOC framework (Simons, 1995, 2000). The LOC framework describes four control levers - diagnostic, interactive, boundary and belief - available for top management to guide organizational activity. The focus on the use of controls by top management is appropriate as it is widely recognized that they have a pivotal role in the success or failure of innovation and learning in organizations (Davila et al., 2009; Simsek, 2009; Smith and Tushman, 2005).

\subsection{MCS for exploitation and exploration}

\subsubsection{Diagnostic control systems}

Diagnostic control systems are considered a negative control lever because they draw managerial attention towards unfavorable variances and potential mistakes made in the implementation of intended strategies. As such, diagnostic systems are associated with mechanistic administrative structures premised upon tight control and highly structured channels of communication (Henri, 2006). This would seem to be consistent with the demands for efficiency implied by exploitation. However, greater performance benefits from exploitation occur when the firm is able to make continual but incremental adaptations to processes and activities, rather than the precise reproduction of pre-specified routines (Benner and Tushman, 2002). The risk with diagnostic control is that discussions triggered by negative variances lead to "corrective action at best" but at worst draw attention towards unproductive topics "such as the believability of the numbers or why things are not better" without any rectifying actions or improvements taking place (Henri, 2006, p. 534).

In the context of exploitation there are a number of reasons why diagnostic systems would be beneficial for enhancing firm performance. First, unproductive discussions emanating from diagnostic mechanisms are likely to occur when managerial preferences are unstable or when objectives cannot be unambiguously codified into quantitative metrics (Chapman, 1997). As exploitation is anchored upon understandings of existing processes and capabilities, knowledge tends to be more explicit in nature (Abernethy and Brownell, 1999). This allows organizational goals to be clearly and precisely specified (Turner and Makhija, 2006). When goals are clearly defined and communicated they help to absorb uncertainty and direct attention towards desired outcomes (McGrath, 2001). Also, by making organizational objectives and progress transparent, diagnostic control systems foster mutual 
commitment and coordinated action towards desired outcomes, leading to higher firm performance (Adler and Chen, 2011; Widener, 2007).

Second, diagnostic control systems are "not simply a constraining influence on managers' behaviors, because monitoring processes highlight problems and motivate managers to achieve their goals, sometimes through novel means" (Mundy, 2010, p. 501). As diagnostic systems specify only the desired outcomes, not the procedures that must be followed, they can provide sufficient space and flexibility for subordinates to experiment with incremental adjustments to their activities (Adler and Chen, 2011). By providing clear goals diagnostic control systems also narrow the field of search, increasing the efficiency of locating solutions to task related problems (McGrath, 2001). This focus encourages single-loop learning through increased depth, rather than scope, of knowledge, necessary to exploit existing technological trajectories (Argyris and Schön, 1978; He and Wong, 2004). Evaluation through targets is also effective for improving the mean performance of groups attempting to converge on a solution to a pre-defined problem (Cheng and Van de Ven, 1996).

For exploration firms, emphasis on diagnostic control systems are unlikely to be associated with significant performance improvements. Exploration entails subordinate experimentation and search outside existing market and technological domains. This requires activities to be loosely connected to outcomes, as learning about unfamiliar terrain is often the result of behaviors that are not goaldirected (McGrath, 2001). Some evidence suggests that diagnostic controls help to constrain excessive innovation and provide the focus and structure necessary to effectively realize emerging opportunities (Cameron, 1986; Chenhall and Morris, 1995). Yet over-emphasizing diagnostic mechanisms can redirect organizational attention towards minimizing performance deviations to meet short-term targets and shorten efforts in the discovery of new knowledge that ultimately limit potential returns to the firm (March, 1973; Osborn, 1998). Diagnostic systems also tend to be aligned with extrinsic reward structures, which can diminish intrinsic motivation required for creativity (Deci and Ryan, 1985; Simons, 1995). Furthermore, objectives for exploration are characterized by less precision and specificity, reducing the ability to use quantitative measures as a means for evaluation (Turner and Makhija, 2006). This leads to the following hypothesis:

H1: Emphasis on diagnostic control systems has a positive association with performance for exploitation firms.

\subsubsection{Interactive control systems}

Interactive control systems are formal information systems that are embedded within patterns of frequent and intense communication centered upon emergent opportunities and strategic uncertainties (Simons, 1995). In contrast to diagnostic systems, interactive systems are a positive control lever as 
dialogue is forward-looking, facilitative and inspirational. This form of control has been found to have a positive effect on firm performance in settings characterized by innovation and change. For instance, Abernethy and Brownell (1999) find that hospitals undergoing strategic redirection have higher performance when budgets are used interactively, while Bisbe and Otley (2004) demonstrate that an interactive use of MCS increases the performance effects of product innovation in mature, medium-sized manufacturing firms. This association with firm performance is expected to hold more generally in an exploration context for at least two reasons.

First, performance in exploration firms is dependent on the discovery of emergent opportunities and creation of new capabilities. Research has shown that much of this transpires through the autonomous experimentation and search activities of lower level managers dispersed throughout a firm (Burgelman, 1991, 2002; Marginson, 2002). To translate potential opportunities and novel insights into commercially viable outputs, however, requires more focused attention and a coordinated allocation of resources that only occurs when top management has recognized and integrated such opportunities into the strategic agenda of the firm. Through involving themselves regularly and personally in the activities of subordinates, interactive control provides top managers access to emergent patterns of activity, enabling the selection and investment of resources into those initiatives that display the most potential for delivering competitive advantage (Simons, 1995). Additionally, the nature of knowledge generated through exploration tends to be more nuanced, subtle, speculative and causally ambiguous than the knowledge developed in exploitative activities (Gupta et al., 2006). This tacit knowledge is less amenable to codification, necessitating verbal communication (Ditillo, 2004; Turner and Makhija, 2006). Using formal information systems in an interactive fashion facilitates the exchange of tacit knowledge that is relevant for guiding opportunity search and deriving performance benefits from new technologies and markets (Hall, 2010).

Second, inertial pressures and cognitive biases tend to result in organizations retaining competencies and routines that have delivered successful outcomes in the past (Smith and Tushman, 2005; LeonardBarton, 1992; Levinthal and March, 1993). Firms pursuing exploration typically face competitive landscapes that are susceptible to technological shifts, such that optimization upon existing knowledge bases will provide only temporary advantage (Levinthal, 1997; D'Aveni, 1994). The potential performance distributions of these environments have longer right-hand tails, meaning that the greatest returns are available to organizations that actively engage in variance-increasing activities (McGrath, 2001). As interactive systems provide a permanent and open forum for debate, they serve as a catalyst to challenge the status quo and question the validity of current action plans. In doing so, organizations are more likely to break out of narrow search routines, increasing the performance potential of the firm (Simons, 1995). 
Interactive control systems are unlikely to be beneficial for exploitation, where the more routine nature of activities and incremental innovative efforts result in less of an information deficit (Simons, 2000; Galbraith, 1973). Interactive systems do not represent an efficient means of control for exploitation firms as they require more substantial resource commitments and managerial attention than diagnostic systems (Widener, 2007). Normal operating activities are disrupted by interactive control efforts if subordinates are encouraged to frequently pursue trial-and-error adjustments (Chenhall and Morris, 1995). Continually debating the underlying assumptions of performance metrics also undermines the validity and motivational potency of performance targets. These arguments are formalized as:

H2: Emphasis on interactive control systems has a positive association with performance for exploration firms.

\subsubsection{Boundary control systems}

Boundary control systems are formal mechanisms used to delineate the acceptable domain of organizational activity (Simons, 1995). These systems are essentially proscriptive in nature, setting restrictions or minimum requirements on subordinate behavior, and circumscribing strategic actions by limiting the scope of opportunity search. Although the exertion of boundaries minimizes available latitude, this does not necessarily mean a reduction in empowerment or motivation (Adler and Chen, 2011; Frow et al., 2010). Rather, this bounded autonomy helps to focus the attention of subordinates towards areas considered critical to the performance of current operations. This is effective for exploitation as employees are discouraged from seeking continual adjustments beyond optimal and timely solutions (Mundy, 2010). Boundary systems also minimize the risk of subordinates pursuing activities that undermine the reliability and continuity of established processes. This is important for exploitation firms as activities are often tightly-coupled (Benner and Tushman, 2002).

Simons (1994) finds that boundary systems have an important role in facilitating strategic renewal, prompting managers to unlearn old routines and paving the way for new frames of reference to be adopted. This suggests that boundary systems have a role in explorative activities as well. However, over time boundary systems tend to restrict experimentation and testing of alternatives to only those domains that have been sanctioned by the organization (Simons, 2000). While this improves the efficiency of local search activities involved in exploitation, it is problematic for exploration as it results in portions of the environment being unexplored and untestable (Rodan, 2005). Although boundary systems provide focus for subordinate activity, setting rigid limits on the scope of search reduces the potential variety of experience and knowledge necessary for maximizing returns to exploratory innovation. The following is therefore expected: 
H3: Emphasis on boundary control systems has a positive association with performance for exploitation firms.

\subsubsection{Belief control systems}

Belief control systems are "the explicit set of organizational definitions that senior managers communicate formally and reinforce systematically to provide basic values, purpose, and direction for the organization" (Simons, 1995, p. 34). Belief systems commonly take the form of mission statements, value statements, credos and statements of purpose (Simons, 1994). The purpose of a belief system is to encourage subordinates to adopt the values and objectives espoused by top management (Widener, 2007). Belief systems, such as mission statements, tend to be constructed in fairly general, value-laden terms, as they are designed to "inspire organisational search and discovery without prescribing the precise nature of the activities" (Mundy, 2010, p. 501).

Belief systems are likely to have the performance benefits for firms pursuing exploration. First, as exploratory firms tend to operate in uncertain conditions it is difficult to explicitly codify boundaries since strategic contexts are subject to constant and unpredictable change. However, core values and beliefs present a relatively stable reference point for individuals to make judgments aligned with the strategic intent of the organization as events unfold (Bartlett and Ghoshal, 1993; Mundy, 2010). Shared values also provide a common basis of understanding, facilitating the exchange of information between organizational members with disparate experiences and knowledge, in order to arrive at new ideas (Hansen, 2002). Second, belief systems enhance the motivation of individuals in settings that require creativity (Simons, 1995). Adler and Chen (2011) argue that belief systems positively affect the identified motivation of individuals through the internalization of organizational values and purpose. Although it is intrinsic motivation that is considered to have the highest effect in generating novel outcomes, it is not mutually exclusive to identified motivation. As such, the internalization of values and strategic intent help to channel creative efforts towards value-generating projects without crowding out intrinsic impetus. Third, belief systems can help prevent the onset of organizational inertia (Simons, 1994). Belief systems permit departure from established routines and expectations when these have drifted from the underlying values of the organization (Mundy, 2010). Varianceincreasing behaviors, which are central to exploratory innovation, are legitimized through shared organizational values (Davila et al., 2009).

Belief systems may benefit exploitation as shared values help to resolve conflicting interests and disagreements thereby facilitating concerted action towards specific targets (Jansen et al., 2008). Identification to group values and goals has also been shown to have positive effects on motivation and task coordination in contexts with routine activities (Adler and Chen, 2011). However, increasing the emphasis on belief systems is an unnecessary use of limited managerial attention, as control can 
be more effectively accomplished through prescriptive means in stable contexts (Ouchi, 1979; Speklé, 2001). Furthermore, placing too much emphasis on belief systems may result in negative returns for exploitation firms by encouraging opportunity-search that deviates too far from existing routines and competencies. Hence it is expected:

H4: Emphasis on belief control systems has a positive association with performance for exploration firms.

\subsubsection{Combined use of control levers}

So far the association between the individual control levers and firm performance has been considered for exploitation and exploration firms. A central contention of Simons (2000, p. 301), however, is that "the power of these levers" resides not in how they are used in isolation but "rather in how they complement each other when used together". This leads to the expectation that there are complementary effects between control levers, that is, greater emphasis on one control lever increases the returns received from the use of another (Milgrom and Roberts, 1995; Widener, 2007). This also implies that control levers used in isolation may be insufficient to enhance performance. Rather the reinforcing effects generated through using control levers in combination might be necessary to achieve significant performance benefits.

Although interdependence is a key theme in the levers of control framework so far there has been somewhat limited insight into the circumstances in which certain combinations are most effective (Frow et al., 2010; Henri, 2006; Mundy, 2010; Tuomela, 2005). The preceding theory development suggests, though, that for exploitation firms, diagnostic and boundary control systems have mutually reinforcing effects (Mundy, 2010). Boundary systems minimize exposure to risk and emphasize depth rather than scope in opportunity search, consistent with exploitation, but in imposing constraints and enforceable sanctions they can decrease the incentive for individuals to innovate even incrementally. However, if subordinates are aware how boundaries connect to organizational goals they may be internalized and support identified motivation (Adler and Chen, 2011). As Mundy (2010) describes, diagnostic controls provide a crucial link with boundary systems by encouraging subordinates to search for performance improvements within an explicitly defined space, which is essential for successful exploitation.

Boundary systems also tend to improve the effectiveness of diagnostic controls. Diagnostic controls communicate desired organizational outcomes, but leave unspecified how those targets are to be achieved. This provides subordinates room to experiment with alterations to existing routines and seek novel solutions to problems (Adler and Chen, 2011). Without explicit boundaries, subordinates have the latitude to make significant changes to existing routines or engage in excessive search and 
experimentation, resulting in increased risk, operational discontinuity and wasted resources (Simons, 1995). Having boundary systems that are clearly tied to enforceable sanctions are particularly important when subordinates are set challenging performance targets as it is in these circumstances that individuals are most tempted to bend the rules (Simons, 2000). By clearly articulating the risks and opportunities to be avoided, subordinate efforts motivated through diagnostic controls are more effective in exploiting existing product markets and firm capabilities. The above discussion leads to the following hypothesis:

H5: For exploitation firms the use of diagnostic (boundary) control systems has a more positive association with performance the higher the emphasis on boundary (diagnostic) control systems.

For firms specializing in exploration, belief and interactive control levers act as complementary systems to enable more effective opportunity search and realization of emergent initiatives (Mundy, 2010; Simons, 2000). As discussed, belief systems are an important mechanism for motivating and guiding exploratory activity. But for emerging opportunities to result in higher firm performance they need to be translated into the strategic agenda of the firm. Through interactive control managers are able to provide increased resources and structure to those initiatives that hold the most potential (Simons, 1995). Without interactive controls, the novel and creative outputs inspired by belief systems may take significantly longer, or even fail, to be effectively realized. Additionally, interactive controls are more likely to be effective when there is a consensus among members on the fundamental values and purpose of the organization (Widener, 2007). When individuals hold divergent values and beliefs attempts to encourage open information exchange and debate can lead to conflict that is divisive, impeding the ability of the firm to interpret and respond to environmental uncertainties (Sorensen, 2002). Disagreements over expectations and objectives also hinder efforts to integrate the complex and non-routine tasks associated with exploration (Ditillo, 2004; Van de Ven, 1986). Through reinforcing a collective frame of reference belief systems increase the effectiveness of interactive controls in generating "focus, integration and fine-tuning" that enhance the performance outcomes of exploratory innovation (Bisbe and Otley, 2004, p. 715). Thus:

H6: For exploration the use of interactive (belief) control systems has a more positive association with performance the higher the emphasis on belief (interactive) control systems.

\subsection{MCS for ambidexterity}

The control requirements for firms that simultaneously pursue contradictory and opposing types of innovation are expected to be fundamentally different from those that specialize (Simsek, 2009). Recent research on managing strategic contradictions posits that ambidextrous firms will be more 
successful when opposing tensions are approached from a both/and rather than from an either/or perspective (Eisenhardt et al., 2010; Schreyogg and Sydow, 2010; Smith and Lewis, 2011). While the latter implies that a choice must be made between strategic agendas, as in the case of specialization, the former encourages contradictions to be embraced simultaneously (Gibson and Birkinshaw, 2004; Smith and Tushman, 2005). In this way managers "recognize and accept the simultaneous existence of contradictory forces" through "paradoxical framing" rather than seeking resolution or elimination of those tensions (Smith and Tushman, 2005, p. 526). By embracing inconsistencies, any movement towards one side is cognitively countered by a feeling of being pulled towards its opposite, fostering an ongoing balance (Andriopoulos and Lewis, 2009; Eisenhardt, 2000). If tensions are ignored or avoided, then the more proximate gains from structural alignment, and psychological biases favoring consistency and certainty, tend to result in resource allocations converging upon existing products and technological developments (Leonard-Barton, 1992; Levinthal and March, 1993).

To effectively manage the competing tensions of exploitation and exploration requires control levers to be combined (Simons, 1995, 2000). Activating levers individually can result in certain strategic demands being avoided or traded off, leading to suboptimal resource allocation or drift towards exploitative investments (Lewis, 2000). Instead, it is necessary to use control levers in combination to generate a dynamic tension that encourages decision makers to simultaneously address demands for both innovation and predictable goal achievement (Simons, 1995). It is therefore expected that the complementary effect of control levers in producing dynamic tension enhances performance in ambidextrous firms, rather than the use of individual levers. While combinations have already been posited for exploitation and exploration firms, these are concerned with the mutually reinforcing effects of positive (interactive and belief) and negative (diagnostic and boundary) control levers. In an ambidextrous context what is required is the joint use of levers that represent countervailing and opposing forces. Although there are a number of possible combinations, diagnostic and interactive control systems tend to work together in guiding the implementation and formulation of strategy, while belief and boundary systems frame the strategic domain of the firm (Simons, 1995, p. 157).

Dynamic tension from the simultaneous and intensive use of interactive and diagnostic controls stimulates dialectically styled interactions and debate (Chenhall, 2004). These interactions help to bring competing demands and opposing viewpoints to light (Van de Ven, 1986). In doing so organizational members are more likely to develop shared understandings and awareness of coexisting tensions, and be less inclined to seek either/or tradeoffs between competing priorities. Instead, such interaction motivates the search for alternate ways of doing things from a both/and perspective, leading to the integration and synthesis of opposing positions (Henri, 2006). Belief and boundary systems similarly operate in tandem to generate tensions surrounding the appropriate domains for opportunity search (Frow et al., 2010; Mundy, 2010). Simultaneous application of both 
systems encourages organizational members to expand exploratory search while being cognizant of the risks that must be avoided to prevent disruption to exploitative routines. This ongoing tension between autonomy and accountability motivates individuals to continually assess when existing boundaries need to be breached to adapt to or take advantage of shifting environmental conditions, or when opportunity search must be limited to avoid excessive risk exposure. Thus the following hypotheses are posed:

H7: The simultaneous use of diagnostic and interactive control systems has a positive association with performance for ambidexterity firms.

H8: The simultaneous use of boundary and belief control systems has a positive association with performance for ambidexterity firms.

The prior hypotheses reflect the magnitude or intensity of using opposing but interdependent levers. This signifies a preference for more of either control rather than less (Widener, 2007). An additional consideration is the relative emphasis given to each control lever. This relative emphasis constitutes the balance between levers. Based on case study analyses, Mundy (2010) contends that balance is central for dynamic tension that effectively contributes to organizational capabilities. Mundy notes, though, that the concept of balance has not been clearly addressed in formal tests of the LOC framework. ${ }^{4}$ The difference between the combined and balanced use of controls is illustrated by the following example (cf. Cao et al., 2009). Consider that Firm A has a score of 5 for interactive and 7 for diagnostic controls, whereas Firm B has a score of 5 for both. Hypothesis 7 leads to the expectation that Firm A will receive a higher performance benefit as the combined magnitude of control use is greater than in Firm B. However, this does not account for the relative imbalance between levers. In an ambidexterity context, this may result in strategic tradeoffs that negatively affect performance as competing tensions are not afforded equivalent attention (March, 1991).

More specifically, placing greater intensity on diagnostic controls relative to interactive systems inhibits experimentation and the search for new opportunities, and may cause discontinuities in the environment to be missed (Cameron, 1986; Chenhall and Morris, 1995). On the other hand, an imbalance towards interactive controls can lead to continual change preventing the efficient conduct of routine activities and a lack of focus on immediate contingencies (Chenhall and Morris, 1995). Placing relatively greater emphasis on belief systems may lead to the consumption of firm resources on excessive experimentation and search (Mundy, 2010; Simons, 1995). Conversely, an imbalance

\footnotetext{
${ }^{4}$ Henri (2006, p. 537), for instance, discusses dynamic tension resulting from using diagnostic and interactive systems simultaneously and intensively as well as from their balanced use. However, Henri models dynamic tension as a product term, reflecting intensity of combined use rather than the relative balance between levers.
} 
towards boundary systems diminishes motivation to seek alternate solutions with higher payoffs and impedes adaptation in dynamic environments (Mundy, 2010). In summary, while the simultaneous and intensive use of levers that represent positive and negative forces helps to create the necessary tension to manage competing demands (Henri, 2006, p. 537), an imbalance between jointly activated levers disrupts this capability, leading to unintended consequences that negatively impact the performance of ambidexterity firms (Mundy, 2010). This leads to the following expectations:

H9: An imbalance between the use of interactive and diagnostic control systems has a negative association with performance for ambidexterity firms.

H10: An imbalance between the use of belief and boundary control systems has a negative association with performance for ambidexterity firms.

\section{Research method}

\subsection{Data collection}

Data for this study were collected through a cross-sectional questionnaire sent to one member of the top management team of a firm. ${ }^{5}$ The target population consisted of a random sample of 1500 firms obtained from the database of CPA Australia. All firms are either independent companies or SBUs with a minimum of 100 employees and \$20 million (AUD) in revenues. Cross-checking characteristics against Dun and Bradstreet and Hoovers databases resulted in 107 firms being removed, leaving a usable population of 1393.

Administration of the survey followed four steps: pre-notification, initial mailing, first follow up, and second follow-up (Dillman, 2000). Respondents were contacted over a period of three months by telephone to create an interest in the survey and ensure that the firm and respondent were appropriate for the study. Questionnaires were sent within a week of the initial contact to the 911 respondents that agreed to participate. The first reminder was a postcard sent one and a half weeks following mailing and the second entailed a follow-up telephone call made to non-respondents after three weeks. A total of 421 questionnaires were received, yielding a response rate of 46.2 percent. Some questionnaires cannot be used in the analysis due to significant missing data or the firm not meeting the criteria of the study. This results in 400 usable responses. ${ }^{6}$ Demographic data are displayed in Table 1.

$<$ Insert Table 1 about here>

\footnotetext{
${ }^{5}$ Top management team is defined as the top two levels of an organization's hierarchy (Henri, 2006).

${ }^{6}$ Questionnaires containing items that appeared to have been missed inadvertently are retained. No item had more than $1.5 \%$ of missing variables. Analysis shows that data are missing completing at random (MCAR, $p>0.10$ ). Values are imputed using the expectation-maximization process (Hair et al., 2006).
} 
Harman's single-factor test is conducted to assess common method bias. The solution returns 14 factors with Eigenvalues greater than one with cumulative variance of 71.8 percent. The first factor explains less than half of the overall variance (20.1 percent) implying that single-source bias is not a significant concern (Podsakoff and Organ, 1986). To assess non-response bias the size and industry of respondent firms are compared to the sample population with no significant differences detected ( $p>0.05$ ). Comparison of construct means and medians between the first and last 20 percent of responses received also show no meaningful differences.

\subsection{Variable measurement}

The variables for this study are based on previously validated constructs where possible. However, a number of these constructs needed to be refined in light of guidelines presented by Rossiter (2002) and Jarvis et al. (2003) for reflective and formative measurement models. Because of these refinements, significant emphasis was given to development and pilot testing of the survey instrument. Pilot testing involved ten interviews with senior managers from medium-to-large organizations. These interviews served to refine the selection of variables, analyze consistency in understanding of survey items, and to remove any undue complexity in item wording. To further establish content and face validity nine academics in the management control discipline reviewed the survey. Items used to measure each construct are detailed in Appendix A. All items are measured on Likert-type scales from one to seven. ${ }^{7}$

Reflective measurement models are assessed through factor analysis, which reveals the relations among observable items and provides support for unidimensionality of constructs, and calculation of Cronbach's alpha, which examines the internal consistency of constructs. Factor analysis is conducted with Maximum Likelihood extraction and oblique rotations. ${ }^{8}$ Results reported in Table 2 show extracted factors with no significant cross-loadings and satisfactory reliability $(\alpha>0.70)$. For formative measurement models, conventional statistical assessments of construct validity are inappropriate (Jarvis et al., 2003; Rossiter, 2002). In formative models directionality runs from the indicators to the construct meaning that indicators do not necessarily covary. Furthermore, as indicators are the defining facets of the construct removal of an indicator may alter the conceptual meaning of the construct and undermine its validity (Bisbe et al., 2007; Rossiter, 2002). Instead, Petter et al. (2007) suggest examining weights and multicollinearity of formative construct items. Very low or negative weightings can indicate that items are unrelated to the construct of interest, while highly correlated

\footnotetext{
${ }^{7}$ The one exception is the control variable of firm age. Firm age is measured as an ordinal variable with five age brackets. As this cannot be interpreted as a continuous measure, firm age is included in the analysis as a dummy variable taking a value of one if the firm is more than 20 years old and zero otherwise (Sandino, 2007).

${ }^{8}$ Principal axis extraction also shows no significant differences in factor loadings.
} 
items suggest that multiple items are tapping into the same facet of the construct. Principal components analysis for formative constructs reveals all weights are positive and above 0.30 (Hair et al., 2006). ${ }^{9}$ Multicollinearity is examined through calculation of variance inflation factors (VIFs). The highest VIF is 4.13. This is below the general tolerance of 10 suggesting multicollinearity between formative indicators is not a significant concern (Diamantopoulos and Winklhofer, 2001). Descriptive statistics for variables used in this study are detailed in Table 3.

<Insert Table 2 about here>

<Insert Table 3 about here>

\subsubsection{Control levers}

Measurement of diagnostic (DIAG) and interactive (INT) control levers are assessed through top management use of budgets and performance measurement systems (PMS). Although multiple systems within a control package can be used in a diagnostic or interactive fashion, it was practically necessary to limit the research scope. Budgets and PMS are selected as these systems have been found to have wide application at the top management level and have been empirically associated with innovation and performance (Abernethy and Brownell, 1999; Bisbe and Otley, 2004; Henri, 2006; Widener, 2007).${ }^{10}$ Respondents answered questions for interactive and diagnostic use of budgets and PMS separately. Scores are summated for firms that use both systems. Diagnostic control (DIAG) is measured through a reflective measurement model. Five items are identified to reflect the main stages of a conventional cybernetic control cycle as described by Simons (1994, 1995, 2000). Some of the items are adaptations of those used by Henri (2006) and Widener (2007), while others are based on Simons (1994, 1995, 2000). As shown in Panel A of Table 2 a single factor solution of the five items is obtained with satisfactory internal reliability $(\alpha=0.89)$.

Interactive control (INT) is based on the formative measurement model defined by Bisbe et al. (2007). From a thematic analysis of Simons' work, Bisbe et al. argue that there are five defining dimensions of the construct: (1) intensive use by top management, (2) intensive use by operating managers, (3) face-to-face challenge and debate, (4) focus on strategic uncertainties, and (5) non-invasive, facilitating and inspirational involvement. Each dimension is captured using a single concrete indicator (Rossiter, 2002). The wording of these indicators is made with reference to prior studies

\footnotetext{
${ }^{9}$ As there is no requirement for indicators to be highly correlated in a formative measurement model common factor analysis is inappropriate. In order to examine item weightings, principal components analysis is used as it retains the unique variance of each item (Petter et al., 2007).

${ }^{10}$ In the survey instrument budgeting is defined as the preparation of budgets, variance analyses and the forecasting of financials. Performance measures or performance measurement systems are defined as including both financial and non-financial indicators that measure multiple dimensions of performance (cf. Bisbe and Otley, 2004; Widener, 2007).
} 
(Abernethy and Brownell, 1999; Bisbe and Otley, 2004; Davila, 2000; Henri, 2006; Naranjo-Gil and Hartmann, 2007; Widener, 2007).

Boundary systems (BOUND) and belief systems (BELIEF) are based on formative measurement models. Analysis of Simons $(1994,1995,2000)$ reveals that boundary systems contain four constitutive dimensions: (1) they define appropriate conduct, (2) they are used to limit search and experimentation, (3) they are actively communicated by top management, and (4) sanctions are applied to subordinates engaging in activities outside stated boundaries irrespective of the outcome. These attributes are defining facets of the construct rather than manifestations of a latent construct. For instance, an organization may have highly detailed codes of conduct, but this does not necessarily imply that top management are active in communicating these to subordinates, or that they apply sanctions irrespective of their outcome. Conversely, some firms may have little formalization but a strong, informally understood code of conduct. A review of the literature shows that belief systems also have four defining attributes: (1) they codify the core values of the firm, (2) they are actively communicated, (3) they are used to create commitment to firm objectives, and (4) they inspire and guide the search for new opportunities (Simons, 1994, 1995, 2000). Like boundary systems, these attributes do not necessarily share a conceptual commonality. For example, an organization may have a codified system of values, but these may not be written with the intent to guide the search for new opportunities or be frequently communicated. The four dimensions of both boundary and belief systems are captured using single concrete indicators (Rossiter, 2002). Some of the items are based on those used by Widener (2007). However, as her operationalizations capture only subsets of the defining attributes of these constructs, additional items were created based on the descriptions of Simons $(1994,1995,2000)$.

\subsubsection{Exploration and exploitation}

Exploration (EXPLORE) and exploitation (EXPLOIT) are elicited through ten items. These items are derived from He and Wong (2004) and Jansen et al. (2006), and have been further validated in a number of subsequent studies (Cao et al., 2009; Jansen et al., 2009; Lubatkin et al., 2006). The items are interpreted as reflective indicators of a higher order construct. Results of a factor analysis using Maximum Likelihood extraction and oblique rotation are shown in Panel B of Table 2. The first two factors correspond with exploration and exploitation respectively (Cao et al., 2009; Jansen et al., 2006; He and Wong, 2004). ${ }^{11}$ Cronbach's Alphas are 0.77 for exploitation and 0.88 for exploration indicating satisfactory reliability.

\footnotetext{
${ }^{11}$ One item (low cost) has a low communality (0.070). It also does not load significantly on the first two factors $(<0.30)$, and hence is dropped from the analysis. This is consistent with the exploratory factor analysis results of Jansen et al. (2006), suggesting that low cost may represent a strategic concern distinct to exploitative innovation.
} 


\subsubsection{Firm performance}

There has been some debate concerning the relative merits of subjective versus objective based assessments of firm performance (e.g. Selto et al., 1995). Chenhall (2003) reports that a number of studies find significant correlations between subjective evaluations and objective measures of performance, while Venkatraman and Ramanujam (1987) write that neither subjective nor objective indicators of performance are fundamentally superior in terms of providing valid and reliable measurement (see also Dunk, 1992). In this study firm performance (PERF) is measured through a subjective instrument. Five items based on a reflective measurement model are assessed: financial performance, sales growth (in new and existing markets), market share and overall performance (Cao et al., 2009; Gupta and Govindarajan, 1986; Widener, 2007). Panel C of Table 2 reveals that all items load on a single factor with satisfactory reliability $(\alpha=0.84)$.

\subsection{Method of analysis}

To examine the association between control systems and firm performance under different innovation modes, subgroups are created using a two-stage cluster analysis (Ketchen and Shook, 1996). Cluster analysis is an appropriate technique as it attempts to locate mutually exclusive groups within a population that share similar attributes. In the first stage the number of clusters and initial centroid values for EXPLORE and EXPLOIT are determined through a hierarchical agglomeration procedure using Ward's method (Everitt et al., 2001). Review of the dendogram and agglomeration coefficients indicate appropriate solutions of two, three and five clusters. A five cluster partition is selected as this solution clearly distinguishes between exploitation, exploration and ambidexterity subgroups. In the second stage a $K$-means clustering analysis is conducted using the initial centroid values. This nonhierarchical procedure fine-tunes the results by allowing cluster memberships to change (Hair et al., 2006). Comparison of hierarchical and $K$-means procedures show a 91.25 percent similarity in cluster membership.

<Insert Table 4 about here>

Results of the cluster analysis are presented in Table 4. ANOVA and Tukey post-hoc multiple comparison results are also reported. Panel A displays the mean values of each cluster on the innovation modes of exploitation and exploration. Cluster 1 places a moderate emphasis on each innovation mode, while cluster 2 exhibits the lowest emphasis. ${ }^{12}$ Cluster 3 is primarily focused on

\footnotetext{
${ }^{12}$ Clusters 1 and 2 are comparable to the "partially mixed" and "no clear preference" clusters reported in Dekker et al. (2013), with similar empirical distribution. It is difficult, however, to provide meaningful conclusions about the strategic positions of these groups. Cluster 1 might be analogous to Porter's "stuck in the middle" position, while cluster 2 could be a "reactor" type (Miles and Snow, 1978). There may also be strategic priorities unrelated to exploration or exploitation innovation modes that these firms pursue.
} 
exploration, cluster 4 on exploitation, with cluster 5 showing a high emphasis on both innovation modes. As the hypothesized relations of this study consider only firms that specialize in either exploration or exploitation, that is, place a high emphasis on one but not the other, and on those that pursue ambidexterity by placing a high emphasis on both exploitation and exploration, only clusters 3 , 4 and 5 are considered in the tests of hypotheses (Gupta et al., 2006; He and Wong, 2004; Dekker et al., 2013; Lillis and van Veen-Dirks, 2008). Panel B of Table 4 shows the average emphasis on control levers across clusters. The general pattern that emerges is that firms with higher levels of innovation place greater emphasis on control levers, with ambidexterity firms using controls the most intensively. Interestingly, there are no significant differences between control levers for exploration (cluster 3) and exploitation (cluster 4) firms. Although this finding does not contradict the hypotheses of this study (as they predict differences in the relative benefits, rather than on the relative emphasis, of control levers) the result is somewhat surprising, suggesting that firms in the sample are on average not in a (theoretically) optimal position regarding control lever choices. ${ }^{13}$

Hypothesized associations are examined using OLS regressions for each subgroup. To test the relations posited in $\mathrm{H} 1$ to $\mathrm{H} 6$ for exploration (cluster 3) and exploitation (cluster 4) subgroups the following model is used:

$$
\begin{aligned}
\text { PERF }_{i}= & \beta_{0}+\beta_{1} \text { DIAG }_{i}+\beta_{2} I_{N T_{i}}+\beta_{3} \text { BOUND }_{i}+\beta_{4} \text { BELIEF }_{i}+\beta_{5} \text { DIAG }_{i} * \text { BOUND }_{i} \\
& +\beta_{6} I_{N T_{i}} * \text { BELIEF }_{i}+\beta_{9-12}\left(\text { CONTROLS }_{i}\right)+\varepsilon_{i}
\end{aligned}
$$

where PERF represents firm performance and DIAG, INT, BOUND and BELIEF represent the emphasis placed on diagnostic, interactive, boundary and belief control systems respectively. The complementary effects of control lever combinations are modeled as bivariate interaction terms. Several control variables (CONTROLS) expected to be associated with firm performance in an innovation context are included in the regression model. Prior research indicates that older firms have greater accumulated experience allowing higher returns from exploitation, while younger firms have greater flexibility facilitating exploration (Jansen et al., 2006). Older firms are also more likely to survive - that is they have higher performance - than younger firms (Hannan and Freeman, 1989; Sandino, 2007). Firm age ( $A G E$ ) is controlled for through a dummy variable taking a value of one if the firm is more than 20 years old and zero otherwise (Sandino, 2007). Larger organizations tend to

\footnotetext{
${ }^{13}$ This might be a consequence of the difficulty of managing innovation, particularly for exploration-type investments where firms frequently experience limited success (Kanter, 2006). The literature also shows that factors other than innovation drive the choice of control levers (e.g. Widener, 2007). If the demands of innovation on control choice conflict with other contextual factors then this can result in suboptimal alignment (Gresov and Drazin, 1997). Finally, the result may indicate that other control attributes need to be considered. For instance, it may not be the relative emphasis on diagnostic control, but attributes such as the performance dimensions that are captured and whether and how these are tied to compensation, which show the most variance across innovation types (see e.g. Dekker et al., 2013).
} 
have higher operating performance than smaller firms (Fama and French, 1995) and have greater availability of resources (Gooding and Wagner, 1985). Firm size (SIZE) is measured as the natural logarithm of the number of full-time employees. As external environmental conditions can affect potential returns from innovation investments, environmental hostility (ENVHOST) and environmental dynamism (ENVDYN) are included (Jansen et al., 2006). Environmental hostility is defined as the degree of threat from competitors for market demand, resources and growth opportunities (Dess and Beard, 1984; Miller and Friesen, 1983). Such conditions favor investments in exploitation while increasing the risk and reducing the potential returns from exploratory innovation (Levinthal and March, 1993; Zahra, 1996). Based on prior literature, environmental hostility is measured as a summated index of three dimensions (Miller and Friesen, 1984; Tan and Lischert, 1994). As dimensions of a firms environment are not necessary related the construct is treated formatively. Environmental dynamism refers to the rate and predictability of change in the environment (Dess and Beard, 1984). Stable environmental conditions allow firms to maximize returns from exploitation while higher financial returns from exploration require dynamic environments that are disruptive to existing market and technological conditions (Jansen et al., 2006). Like hostility, environmental dynamism is also treated as a formative construct, and is measured as a summated index across five items on the rate of change and the degree of predictability (Chenhall and Morris, 1993; Gordon and Narayanan, 1984). Principal component analysis for ENVHOST and $E N V D Y N$ show that all item loadings are positive and well above the general threshold of 0.3 (Hair et al., 2006). The highest VIF calculated is 1.92 .

To assess the predicted associations in $\mathrm{H} 7$ to $\mathrm{H} 10$ for the ambidexterity subgroup (cluster 5) requires inclusion of terms to reflect the balance, or relative magnitude, between control levers. Balance is modeled as the absolute difference $(A B S$ ) between control lever emphasis (Cao et al., 2009; He and Wong, 2004; Ylinen and Gullkvist, 2012). The empirical model is as follows:

$$
\begin{aligned}
\text { PERF }_{i} & =\beta_{0}+\beta_{1} \text { DIAG }_{i}+\beta_{2} \text { INT }_{i}+\beta_{3} \text { BOUND }_{i}+\beta_{4} \text { BELIEF }_{i}+\beta_{5} \text { DIAG }_{i} * \text { INT }_{i} \\
& +\beta_{6} \text { BOUND }_{i} * \text { BELIEF }_{i}+\beta_{7} A B S\left[\text { DIAG }_{i}-\text { INT }_{i}\right]+\beta_{8} A B S\left[\text { BOUND }_{i}-\text { BELIEF }_{i}\right] \\
& +\beta_{9-12}\left(\text { CONTROLS }_{i}\right)+\varepsilon_{i}
\end{aligned}
$$

where $A B S[D I A G-I N T]$ is the absolute difference between DIAG and INT variables and $A B S[B O U N D-B E L I E F]$ represents the absolute difference between BOUND and BELIEF.

\section{Results}

A correlation matrix is presented in Table 5. All correlations are below $r=0.6$ except for the association between DIAG and INT. However, this is consistent with correlations reported in prior 
analyses (Henri, 2006; Widener, 2007). Table 6 presents the regression results for both exploitation firms and exploration firms. Models 1 and 3 represent the baseline regressions that include individual control levers and firm control variables. Models 2 and 4 introduce the hypothesized interaction terms for exploitation $(D I A G * B O U N D)$ and exploration (INT* BELIEF) as shown in Equation (1). Results for the ambidexterity subgroup are provided in Table 7 . Model 1 represents the baseline regression. Model 2 introduces the hypothesized interaction terms for the ambidexterity subgroup (INT*DIAG and BOUND * BELIEF), while Model 3 adds the difference terms (ABS[DIAG-INT] and $A B S[B O U N D-B E L I E F])$ to the baseline model. Model 4 presents the full hypothesized model as shown in Equation (2). Prior to the construction of interaction and difference terms, independent variables are mean-centered to reduce potential effects of multicollinearity (Cohen et al., 2003). The maximum VIF across subgroup models is 2.36 , which is well below the general threshold of 10 (Hair et al., 2006). ${ }^{14}$

<Insert Table 5 about here>

<Insert Table 6 about here>

Regarding the effects of individual control levers on firm performance for the exploitation subgroup (Table 6), Model 2 shows that the coefficients for DIAG $(\beta=0.314, p<0.05)$ and BOUND $(\beta=$ $0.258, p<0.05)$ are positive and significant, providing support for $\mathrm{H} 1$ and $\mathrm{H} 3$. For the exploration subgroup (Table 6), Model 4 reveals a positive and significant coefficient for INT $(\beta=0.317, p<$ 0.05), supporting $\mathrm{H} 2$. The coefficient for BELIEF is positive but insignificant $(\beta=0.232$, n.s.). $\mathrm{H} 4$ is not supported.

H5 posits that the interaction of diagnostic and boundary systems has a positive association with performance for exploitation firms. The interaction term DIAG*BOUND in Model 2 of Table 6 is negative and insignificant, providing no support for $\mathrm{H} 5$ ( $\beta=-0.109$, n.s.). H6 expects that the interaction of interactive and belief controls is positively related to firm performance for exploration firms. In Model 4 of Table 6 the interaction term INT * BELIEF is negative and insignificant $(\beta=-$ 0.014 , n.s.). H6 is not supported.

<Insert Table 7 about here>

For the ambidexterity subgroup, the results of Model 2 in Table 7 reveal that the interaction of diagnostic and interactive controls $(D I A G * I N T)$ has a positive and significant association with firm

\footnotetext{
${ }^{14}$ Non-hypothesized control lever combinations are also examined for each subgroup. There are no significant results.
} 
performance $(\beta=0.223, p<0.05)$, providing support for $\mathrm{H} 7$. To further examine the interaction term a simple slope analysis is displayed in Fig. $2 .{ }^{15}$ Consistent with H7, the plot shows that firms that simultaneously combine high emphasis of DIAG and INT have higher firm performance. However, $\mathrm{H} 8$ is not supported, as the interaction of BOUND * BELIEF is negative and insignificant $(\beta=-0.051$, n.s.). Unexpectedly, the main effect of BELIEF is positive and significant in Models 1 through 3.

<Insert Fig. 2. about here>

H9 posits that an imbalance between the emphasis on diagnostic and interactive controls has a negative association with firm performance. The coefficient of $A B S[D I A G-I N T]$ in Model 3 of Table 7 is negative and significant $(\beta=-0.244, p<0.05)$, providing support for $\mathrm{H} 9$. The balance term $A B S[B O U N D-B E L I E F]$ is insignificant $(\beta=0.001$, n.s.). $\mathrm{H} 10$ is not supported. As hypotheses regarding combined and balanced use of control levers may be alternate and competing explanations of performance in ambidexterity firms, Model 4 includes all hypothesized terms. Both interaction $(\beta=$ $0.169, p<0.10)$ and difference $(\beta=0.186, p<0.10)$ terms for DIAG and INT are marginally significant, providing some additional support for $\mathrm{H} 7$ and $\mathrm{H} 9$.

\section{Discussion}

These findings contribute to the growing literature investigating the role of MCS in innovation settings in a number of ways. First, while prior research has found that flexible and interactive control structures are generally beneficial for innovation, the results of this study suggest that their effectiveness is dependent on the particular mode of innovation pursued by the firm. Specifically, the emphasis on interactive control use is associated with enhanced performance for firms engaged in exploratory innovation, but not for exploitation. This is consistent with arguments that more active roles of accounting are suited to contexts where there is significant uncertainty concerning the consequences of action (Ahrens and Chapman, 2004; Chapman, 1997). The results also support the conclusions of Bisbe and Otley (2004) that interactive controls affect firm performance by increasing the effectiveness of innovation processes (moderation effect) rather than through increasing the propensity of the firm to experiment with new products and technologies (mediation effect) (cf. Henri, 2006; Widener, 2007).

Second, the results indicate that the more passive and conventional uses of accounting controls have a positive role for innovation. In organizations concerned with local knowledge search and refinements to first-order competencies, greater emphasis on diagnostic controls can provide sufficient space and

\footnotetext{
${ }^{15}$ Simple slopes are the partial derivative of regression equations containing interaction terms, conducted at one standard deviation above and below the mean (Cohen et al., 2003).
} 
motivation for subordinates to experiment albeit in a more limited manner. Although this potential is recognized by Simons (1995), the literature has generally maintained that diagnostic controls limit the capacity of a firm to innovate as they are associated with and reinforce mechanistic control structures (Henri 2006). Instead the results of this study suggest that the use of diagnostic control is important for performance in firms seeking to exploit existing markets and technological capabilities (Benner and Tushman, 2003).

Third, the study examines the effectiveness of the full range of control levers and analyzes potential complementary effects. Understanding interdependencies between levers is essential for organizational performance (Siggelkow, 2002), yet there has been relatively little investigation into how and when control levers are combined (Mundy, 2010). For exploitation and exploration firms the results suggest, however, that levers act as supplementary rather than complementary controls. Specifically, for exploitation firms, boundary and diagnostic systems are independently related to performance. A possible explanation is found in the framework presented by Davila et al. (2009, p. 299), which considers control variation across incremental and radical innovation, and autonomous and induced strategic activity. Whereas diagnostic systems represent innovation agendas constructed through the deliberate planning activities of top management at the strategy formation stage, boundary systems provide structure for emergent activity at lower organizational levels during implementation phases. Although the two systems may be interrelated in an organization (Mundy, 2010; Widener, 2007), the effect on performance of one system is not necessarily conditional on the other as they are often spatially and temporally separated. Similar reasoning is provided for interactive and belief systems, although the results of this study suggest that emphasis is required only on the former for enhancing the performance returns from exploration. In an exploration setting the internalization of shared values and beliefs is facilitated through the lateral interactions and mutual exchanges of organizational members, resulting in effective social control without the extensive use of formal belief systems (Ouchi, 1979). The interaction between informal and formal controls in innovation settings certainly requires further investigation.

The interrelations between control levers are important in the context of ambidexterity. The results of this study are consistent with Simons' $(1995,2000)$ core argument that dynamic tension generated from the interplay between opposing levers is necessary to effectively balance competing strategic priorities. Prior studies have suggested that there is universal benefit from using performance measurement systems both diagnostically and interactively (Widener, 2007), but particularly for those facing environmental uncertainty and valuing flexibility (Henri, 2006). The results of this study indicate that dynamic tension may be most beneficial for firms that explicitly face contradictory strategic agendas and coexisting pressures for flexibility, creativity and change, against those of consistency, efficiency and predictability. However, results do not support the expected 
complementary effects of boundary and belief systems. Rather, there is weak evidence indicating that belief systems have an independent association with performance. Emphasizing belief systems may be particularly pertinent in an ambidexterity context as prioritizing core values provides a foundation for reconciling conflicting interests and priorities that surface through the use of other levers (O'Reilly and Tushman, 2008; Simons, 2010; Widener, 2007).

Finally, the study provides evidence to suggest that not only are the simultaneous and intensive uses of diagnostic and interactive systems important for ambidexterity firms, but also the relative balance between these levers. This supports Mundy's (2010) assertion that balance is essential for generating dynamic tension to effectively support organizational capabilities. In a context of innovation specialization the firm makes either/or decisions to emphasize certain types of activity over others. By placing greater emphasis on either negative or positive control levers, managers can push the balance towards exploitation or exploration. For ambidextrous firms, opposing tensions cannot be traded off but must be approached from a both/and perspective (Smith and Tushman, 2005). An imbalance between diagnostic and interactive control levers can result in either/or decisions that negatively affect the capacity of the organization to jointly pursue exploitative and exploratory innovations. It should be noted that results are relatively weak when assessing the relative effect of both combined intensity and balanced use of control levers. More research is required to gain a deeper understanding of how balance and dynamic tension operate in ambidexterity contexts.

\section{Conclusion}

This study provides evidence on how patterns of MCS use associated with enhanced performance vary across different innovation modes. Much of the prior literature considers the association between MCS and the extent of innovation in a particular context, such as new product development, rather than variations in innovation characteristics (Davila et al., 2009). This study addresses this gap by investigating how MCS are used by top management in firms that pursue either or both exploration and exploitation. The study also extends the stream of research into the levers of control framework. By examining the full range of levers this study reveals how control systems are used individually and in combination to enhance the performance effects of innovation. The results show that control levers in firms that specialize in one mode of innovation have supplementary rather than complementary effects on performance. Interactive control use is found to be associated with performance in exploration firms while exploitation firms tend to benefit from emphasizing diagnostic and boundary systems. In ambidexterity firms that jointly pursue exploitation and exploration, it is the balanced and combined use of diagnostic and interactive controls to create dynamic tension that matter for enhanced performance. 
This study is subject to certain limitations. First, as this study uses data obtained from a survey instrument it may be affected by common method bias. However, significant attention was given to construct development and survey implementation, while diagnostic tests suggest that any bias is unlikely to be a significant concern. Second, given the cross-sectional nature of this study, only the contemporaneous position of a firm with respect to exploitation and exploration is considered. This assumes that the strategic position of a firm with respect to innovation is relatively stable over time (Cao et al., 2009). Although some firms in the sample may be in the process of strategic shifts, the number in transition is likely to be relatively small. Future research could examine how MCS are implicated in shifting between exploitation and exploration modes. Third, the distinction between exploration and exploitation in this study relates to the strategic emphasis a firm places on particular innovation priorities, but does not directly capture the different types of learning, patterns of knowledge search, and firm resources and capabilities that are conceptually associated with these innovation modes. Exploration and exploitation should also not be confused with incremental and radical innovation. While the former refer to the ex-ante objectives of the firm, the latter relate to expost outcomes (He and Wong, 2004). Future research could analyze how these different individual and firm attributes are related in understanding more specifically the influence of MCS on organizational capabilities and performance outcomes.

The fourth limitation relates to the measurement of firm performance. In this study performance is assessed through a subjective instrument that captures a limited spectrum of dimensions. The results should be interpreted with care regarding possible biases in the measure. Fifth, the analysis is concerned only with the consequences of control use given the innovation mode of the firm. Antecedents to the choice of controls and innovation types are not examined as this poses conflicting methodological assumptions (Gerdin and Greve, 2008). Sixth, interactive and diagnostic levers are conceptualized in terms of the use of accounting based controls. Although this is consistent with recent literature (Henri, 2006; Widener, 2007) it would be interesting to examine alternate mechanisms across different innovation types to assess whether there are effective control substitutes. The study is also limited to the firm level of analysis. While prior studies have given attention to the role and consequences of MCS at operational levels (e.g. Jørgensen and Messner, 2009), there is likely much to learn from the dynamics between control structures at different organizational levels in managing different modes of innovation. 


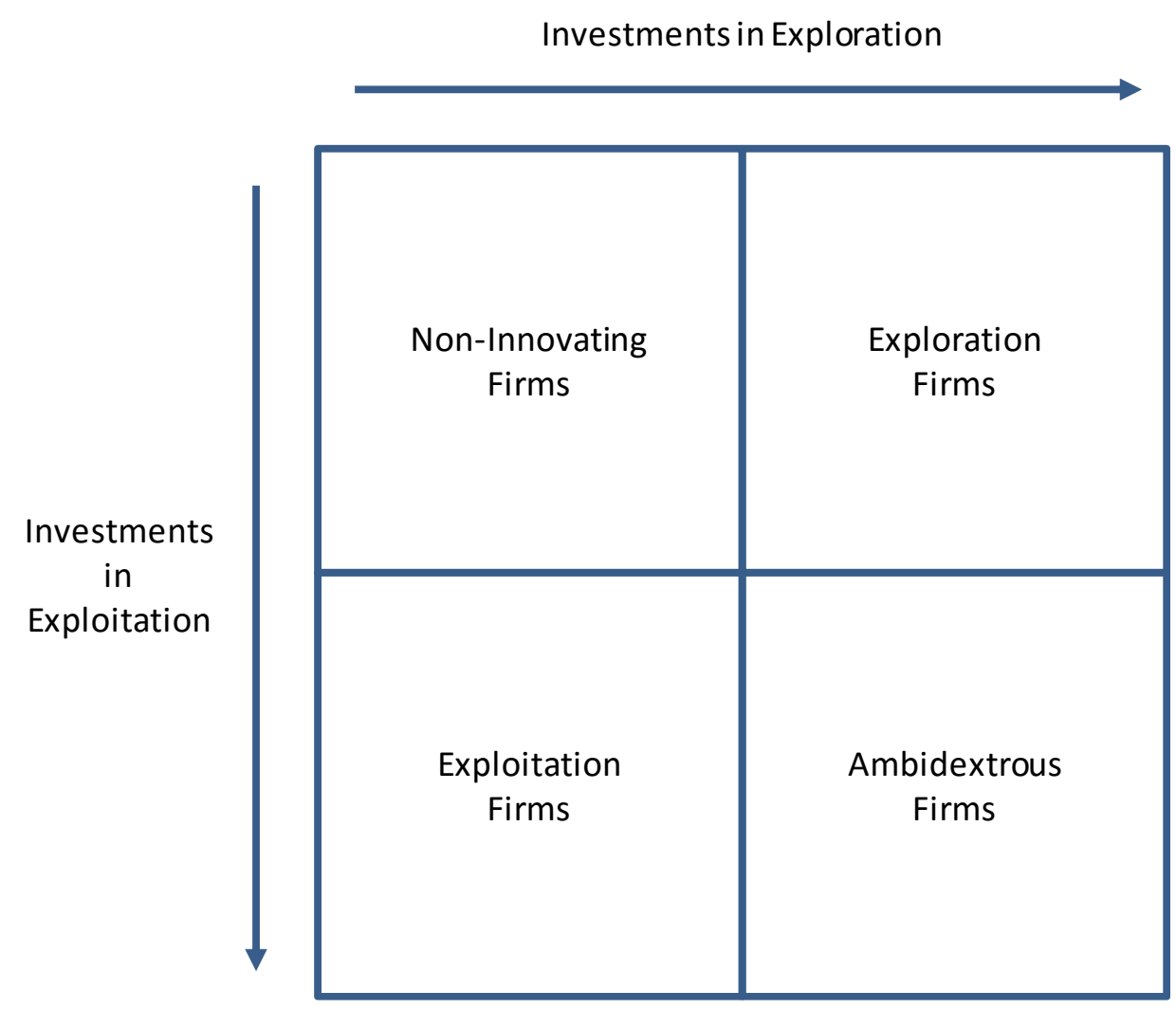

Fig. 1. Representation of innovation modes 


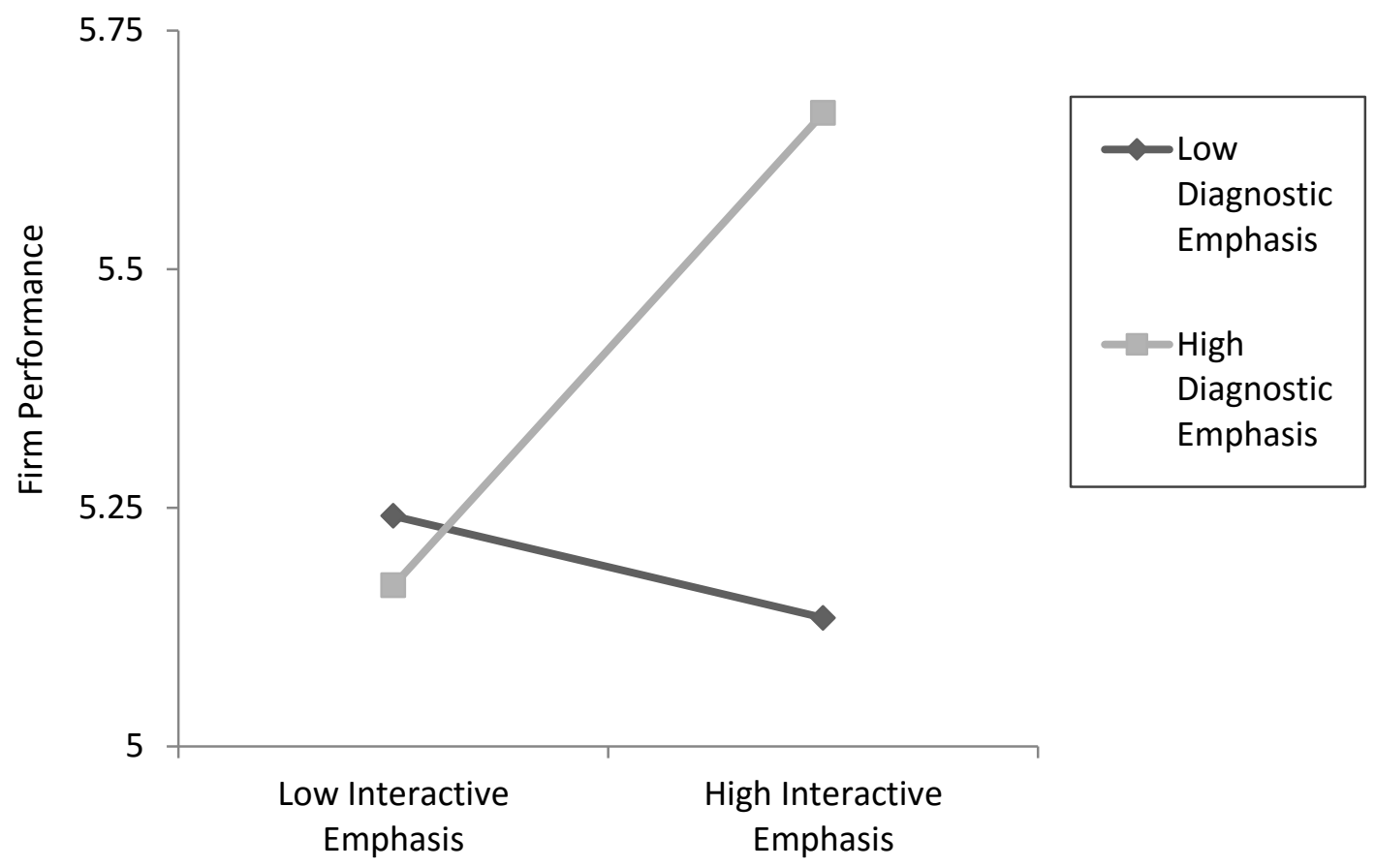

Fig. 2. Simple slope analysis of $D I A G * I N T$ interaction for ambidexterity subgroup 
Table 1

Demographic Data

Panel A: Number of employees

$1-250$

251-500

501-1000

1001-2500

32

$2500+$

Total

400

Panel B: Industry

Agriculture, forestry, fishing 10

Mining

Construction

26

Manufacturing

151

Transportation, utilities

31

Wholesale

22

Retail

20

Finance, insurance, real estate $\quad 41$

Services $\quad 78$

Other 3

Total 400 
Table 2

Factor analysis of reflective constructs

Panel A: Diagnostic Control

Identify critical performance measures $\quad 0.784$

Set targets $\quad 0.799$

Monitor progress $\quad 0.839$

Correct deviations from targets $\quad 0.758$

Review key areas of performance $\quad 0.756$

Eigenvalue $\quad 3.48$

Variance explained $\quad 69.6 \%$

Cronbach's Alpha $\quad 0.89$

KMO Sampling Adequacy $\quad 0.859$

Bartlett's Test of Sphericity $\quad 0.000$

Panel B: Exploitation and Exploration Exploration

Being first to market

0.849

Exploitation

Developing new generation capabilities $\quad 0.816$

0.222

0.285

Frequent new product introductions

0.803

0.216

Experimenting with new products

0.682

0.221

Opening up new markets

0.700

0.250

Improving quality of existing products

0.283

0.774

Modifications to existing products

0.314

0.598

Efficiency of existing products

0.120

0.771

Economies of scale

0.168

0.583

Eigenvalue

$3.82 \quad 1.99$

Variance explained

$42.4 \%$

Cronbach's Alpha

0.77

$22.1 \%$

KMO Sampling Adequacy

Bartlett's Test of Sphericity

0.846

0.000

Panel C: Firm Performance

Financial performance

0.786

Sales growth of new markets $\quad 0.620$

Sales growth of existing markets $\quad 0.592$

Relative market share $\quad 0.628$

Overall performance $\quad 0.933$

Eigenvalue $\quad 3.08$

Variance explained $\quad 61.6 \%$

Cronbach's Alpha $\quad 0.84$

KMO Sampling Adequacy $\quad 0.776$

Bartlett's Test of Sphericity $\quad 0.000$

a Extraction method: Maximum-Likelihood.

${ }^{b}$ Rotation method: Direct Oblimin with Kaiser normalization.

${ }^{c}$ Bold indicates the loadings of the items that represent the factor.

d See Appendix A for complete wording of survey items. 
Table 3

Descriptive statistics

\begin{tabular}{lccccccc} 
& & & & \multicolumn{2}{c}{ Actual Range } & \multicolumn{2}{c}{ Theoretical Range } \\
\multicolumn{1}{c}{ Variable } & Mean & Median & Std Dev & Min & Max & Min & Max \\
\hline DIAG & 5.51 & 5.60 & 0.83 & 1.90 & 7.00 & 1.00 & 7.00 \\
INT & 4.78 & 4.90 & 1.03 & 1.40 & 7.00 & 1.00 & 7.00 \\
BOUND & 4.68 & 4.75 & 1.03 & 1.50 & 7.00 & 1.00 & 7.00 \\
BELIEF & 4.53 & 4.75 & 1.36 & 1.00 & 7.00 & 1.00 & 7.00 \\
EXPLOIT & 4.92 & 5.00 & 0.90 & 1.00 & 7.00 & 1.00 & 7.00 \\
EXPLORE & 4.25 & 4.20 & 1.22 & 1.00 & 7.00 & 1.00 & 7.00 \\
PERF & 4.70 & 4.80 & 0.93 & 1.40 & 7.00 & 1.00 & 7.00 \\
AGE & 0.67 & 1.00 & 0.47 & 0.00 & 1.00 & 0.00 & 1.00 \\
SIZE & 5.82 & 5.63 & 0.91 & 4.61 & 8.70 & - & - \\
ENVHOST & 4.43 & 4.33 & 0.88 & 2.33 & 7.00 & 1.00 & 7.00 \\
ENVDYN & 3.67 & 3.70 & 0.83 & 1.30 & 6.20 & 1.00 & 7.00 \\
\hline
\end{tabular}

DIAG: emphasis on diagnostic control systems; INT: emphasis on interactive control systems; BOUND: emphasis on boundary control systems; BELIEF: emphasis on belief control systems; EXPLOIT: extent to which the firm pursues exploitation; EXPLORE: extent to which the firm pursues exploration; PERF: subjective assessment of firm performance; AGE: dummy variable equal to 1 if the firm is at least 20 years old, otherwise 0; SIZE: natural logarithm of the number of employees in the firm; ENVHOST: degree of hostility in the firm's environment; ENVDYN: degree of dynamism in the firm's environment. 
Table 4

Difference tests of cluster means for strategic priorities and control levers

\begin{tabular}{|c|c|c|c|c|c|c|c|c|}
\hline & $\begin{array}{l}\text { Cluster 1: } \\
\text { Moderate } \\
\text { Innovation } \\
(n=93)\end{array}$ & $\begin{array}{l}\text { Cluster 2: } \\
\text { Low } \\
\text { Innovation } \\
(n=61)\end{array}$ & $\begin{array}{l}\text { Cluster 3: } \\
\text { Exploration } \\
\quad(n=61)\end{array}$ & $\begin{array}{l}\text { Cluster 4: } \\
\text { Exploitation } \\
\quad(n=80)\end{array}$ & $\begin{array}{l}\text { Cluster } 5: \\
\text { Ambidexterity } \\
(n=105)\end{array}$ & F-Test & $p$-value & $\begin{array}{l}\text { Cluster mean } \\
\text { differences }\end{array}$ \\
\hline \multicolumn{9}{|c|}{ Panel A: Innovation focus } \\
\hline EXPLOIT & $\begin{array}{l}4.31 \\
(0.48)\end{array}$ & $\begin{array}{l}3.97 \\
(0.82)\end{array}$ & $\begin{array}{c}4.43 \\
(0.50)\end{array}$ & $\begin{array}{l}5.64 \\
(0.37)\end{array}$ & $\begin{array}{l}5.76 \\
(0.40)\end{array}$ & 207.88 & 0.000 & $\mathrm{C} 4, \mathrm{C} 5>\mathrm{C} 1, \mathrm{C} 3>\mathrm{C} 2$ \\
\hline EXPLORE & $\begin{array}{l}4.14 \\
(0.31)\end{array}$ & $\begin{array}{l}2.68 \\
(0.60)\end{array}$ & $\begin{array}{l}5.43 \\
(0.47)\end{array}$ & $\begin{array}{l}3.18 \\
(0.76)\end{array}$ & $\begin{array}{l}5.38 \\
(0.64)\end{array}$ & 343.68 & 0.000 & $\mathrm{C} 3, \mathrm{C} 5>\mathrm{C} 1>\mathrm{C} 4>\mathrm{C} 2$ \\
\hline \multicolumn{9}{|c|}{ Panel B: Control levers } \\
\hline DIAG & $\begin{array}{l}5.32 \\
(0.89)\end{array}$ & $\begin{array}{l}5.25 \\
(0.91)\end{array}$ & $\begin{array}{l}5.47 \\
(0.77)\end{array}$ & $\begin{array}{l}5.56 \\
(0.79)\end{array}$ & $\begin{array}{l}5.80 \\
(0.71)\end{array}$ & 6.35 & 0.000 & $\mathrm{C}^{*}>\mathrm{C} 1, \mathrm{C} 2, \mathrm{C}^{*}$ \\
\hline INT & $\begin{array}{l}4.52 \\
(0.96)\end{array}$ & $\begin{array}{c}4.27 \\
(1.14)\end{array}$ & $\begin{array}{l}4.80 \\
(0.96)\end{array}$ & $\begin{array}{l}4.74 \\
(0.99)\end{array}$ & $\begin{array}{l}5.34 \\
(0.82)\end{array}$ & 14.68 & 0.000 & $\begin{array}{c}\mathrm{C} 5>\mathrm{C} 1, \mathrm{C} 2, \mathrm{C} 3, \mathrm{C} 4 \\
\mathrm{C} 3, \mathrm{C} 4>\mathrm{C} 2\end{array}$ \\
\hline BOUND & $\begin{array}{c}4.37 \\
(1.08)\end{array}$ & $\begin{array}{c}4.42 \\
(1.07)\end{array}$ & $\begin{array}{l}4.86 \\
(0.97)\end{array}$ & $\begin{array}{l}4.77 \\
(0.96)\end{array}$ & $\begin{array}{l}4.93 \\
(0.97)\end{array}$ & 5.44 & 0.000 & $\begin{array}{c}\mathrm{C} 3, \mathrm{C} 4^{*}, \mathrm{C} 5>\mathrm{C} 1^{*} \\
\mathrm{C} 5>\mathrm{C} 2\end{array}$ \\
\hline BELIEF & $\begin{array}{c}4.19 \\
(1.42)\end{array}$ & $\begin{array}{c}4.26 \\
(1.37)\end{array}$ & $\begin{array}{c}4.61 \\
(1.27)\end{array}$ & $\begin{array}{c}4.48 \\
(1.36)\end{array}$ & $\begin{array}{c}4.99 \\
(1.22)\end{array}$ & 5.34 & 0.000 & $\mathrm{C} 5^{*}>\mathrm{C} 1, \mathrm{C} 2, \mathrm{C} 4^{*}$ \\
\hline
\end{tabular}

EXPLOIT: extent to which the firm pursues exploitation; EXPLORE: extent to which the firm pursues exploration; DIAG: emphasis on diagnostic control systems; INT: emphasis on interactive control systems; BOUND: emphasis on boundary control systems; BELIEF: emphasis on belief control systems.

a Standard deviations reported in parentheses.

b Tukey post-hoc tests for cluster mean differences reported at $p<0.05$. Pairs denoted by an asterisk $\left(^{*}\right)$ are significant at the $p<0.10$ level. 
Table 5

Pearson correlations between variables

\begin{tabular}{|c|c|c|c|c|c|c|c|c|c|c|c|}
\hline & DIAG & INT & BOUND & BELIEF & EXPLOIT & EXPLORE & PERF & AGE & SIZE & ENVHOST & ENVDYN \\
\hline DIAG & 1 & & & & & & & & & & \\
\hline INT & $.645^{\star \star \star}$ & 1 & & & & & & & & & \\
\hline BOUND & $.264^{\star * *}$ & $.358^{\star \star \star}$ & 1 & & & & & & & & \\
\hline BELIEF & $.233^{\star * *}$ & $.367^{\star \star \star}$ & $.474^{\star * *}$ & 1 & & & & & & & \\
\hline EXPLOIT & $.296^{\star \star *}$ & $.329^{\star * *}$ & $.231^{\star * *}$ & $.226^{\star \star \star}$ & 1 & & & & & & \\
\hline EXPLORE & $.144^{\star \star *}$ & $.269^{\star \star *}$ & $.149^{\star \star \star}$ & $.173^{\star \star \star}$ & $.273^{\star \star \star}$ & 1 & & & & & \\
\hline PERF & $.303^{* * *}$ & $.334^{\star * *}$ & $.190^{* * *}$ & $.277^{* \star *}$ & $.268^{\star \star *}$ & $.261^{* * *}$ & 1 & & & & \\
\hline AGE & $.101^{* *}$ & .065 & $.121^{\star \star}$ & $.116^{* \star}$ & .066 & .024 & $.112^{\star \star}$ & 1 & & & \\
\hline SIZE & .051 & $.158^{\star \star \star}$ & .042 & $.140^{\star \star *}$ & .066 & -.016 & .077 & $.174^{\star \star \star}$ & 1 & & \\
\hline ENVHOST & .029 & $.138^{\star \star \star}$ & .078 & $.132^{\star \star \star}$ & $.185^{\star \star \star}$ & $.170^{\star \star \star}$ & .020 & $-.085^{\star}$ & .081 & 1 & \\
\hline ENVDYN & -.061 & -.007 & $.115^{\star *}$ & .045 & $.155^{\star \star \star}$ & $.186^{\star * *}$ & $-.133^{\star \star \star}$ & -.022 & -.018 & $.264^{\star \star *}$ & 1 \\
\hline
\end{tabular}

DIAG: emphasis on diagnostic control systems; INT: emphasis on interactive control systems; BOUND: emphasis on boundary control systems; BELIEF: emphasis on belief control systems; EXPLOIT: extent to which the firm pursues exploitation; EXPLORE: extent to which the firm pursues exploration; PERF: subjective assessment of firm performance; AGE: dummy variable equal to 1 if the firm is at least 20 years old, otherwise 0; SIZE: natural logarithm of the number of employees in the firm; ENVHOST: degree of hostility in the firm's environment; ENVDYN: degree of dynamism in the firm's environment.

* $p<.10$ (two-tailed)

** $\quad p<.05$ (two-tailed)

*** $\quad p<.01$ (two-tailed). 
Table 6

Results of OLS Regressions of Control Levers on Firm Performance for Exploitation and Exploration Subgroups

\begin{tabular}{|c|c|c|c|c|c|c|c|c|}
\hline & \multicolumn{4}{|c|}{ Exploitation Subgroup $(\mathrm{N}=80)$} & \multicolumn{4}{|c|}{ Exploration Subgroup $(\mathrm{N}=61)$} \\
\hline & \multicolumn{2}{|c|}{ Model 1} & \multicolumn{2}{|c|}{ Model 2} & \multicolumn{2}{|c|}{ Model 3} & \multicolumn{2}{|c|}{ Model 4} \\
\hline & Coefficient & t-value & Coefficient & t-value & Coefficient & t-value & Coefficient & t-value \\
\hline \multicolumn{9}{|l|}{ Control Levers } \\
\hline DIAG & 0.295 & $2.079^{\star *}$ & 0.314 & $2.220^{* *}$ & 0.002 & -0.011 & 0.002 & 0.011 \\
\hline INT & -0.008 & -0.053 & -0.039 & -0.253 & 0.323 & $2.214^{\star *}$ & 0.317 & $2.029^{* *}$ \\
\hline BOUND & 0.273 & $2.300^{* *}$ & 0.258 & $2.119^{* *}$ & -0.253 & $-1.729^{\star}$ & -0.250 & -1.659 \\
\hline BELIEF & 0.093 & 0.786 & 0.091 & 0.771 & 0.247 & 1.606 & 0.232 & 1.448 \\
\hline \multicolumn{9}{|l|}{ Interaction Terms } \\
\hline DIAG x BOUND & & & -0.109 & -0.970 & & & -0.057 & -0.437 \\
\hline INT x BELIEF & & & -0.108 & -0.974 & & & -0.014 & -0.105 \\
\hline \multicolumn{9}{|l|}{ Firm Controls } \\
\hline AGE & 0.161 & 1.499 & 0.171 & 1.596 & 0.134 & 1.109 & 0.152 & 1.181 \\
\hline SIZE & 0.007 & 0.065 & 0.002 & 0.021 & 0.224 & $1.779^{\star}$ & 0.211 & 1.609 \\
\hline ENVHOST & -0.065 & -0.593 & -0.090 & -0.819 & -0.073 & -0.598 & -0.070 & -0.555 \\
\hline ENVDYN & -0.069 & -0.632 & -0.050 & -0.449 & -0.058 & -0.451 & -0.058 & -0.435 \\
\hline R-Sq. & \multicolumn{2}{|c|}{0.260} & \multicolumn{2}{|c|}{0.288} & \multicolumn{2}{|c|}{0.306} & \multicolumn{2}{|c|}{0.309} \\
\hline Adj. R-Sq. & \multicolumn{2}{|c|}{0.176} & \multicolumn{2}{|c|}{0.185} & \multicolumn{2}{|c|}{0.200} & \multicolumn{2}{|c|}{0.171} \\
\hline$F$-Value & \multicolumn{2}{|c|}{3.114} & \multicolumn{2}{|c|}{2.797} & \multicolumn{2}{|c|}{2.870} & \multicolumn{2}{|c|}{2.241} \\
\hline Sig. $F$ & \multicolumn{2}{|c|}{0.005} & \multicolumn{2}{|c|}{0.006} & \multicolumn{2}{|c|}{0.010} & \multicolumn{2}{|c|}{0.030} \\
\hline
\end{tabular}

PERF: subjective assessment of firm performance; DIAG: emphasis on diagnostic control systems; INT: emphasis on interactive control systems BOUND: emphasis on boundary control systems; BELIEF: emphasis on belief control systems; AGE: dummy variable equal to 1 if the firm is at least 20 years old, otherwise 0; SIZE: natural logarithm of the number of employees in the firm; ENVHOST: degree of hostility in the firm's environment; ENVDYN: degree of dynamism in the firm's environment.

a Standardized coefficients reported.

* $\quad p<.10$ (two-tailed).

** $\quad p<.05$ (two-tailed)

$\star * * \quad p<.01$ (two-tailed) 
Table 7

Results of OLS Regressions of Control Levers on Firm Performance for Ambidexterity Subgroup

\begin{tabular}{|c|c|c|c|c|c|c|c|c|}
\hline & \multicolumn{2}{|c|}{ Model 1} & \multicolumn{2}{|c|}{ Model 2} & \multicolumn{2}{|c|}{ Model 3} & \multicolumn{2}{|c|}{ Model 4} \\
\hline & Coefficient & t-value & Coefficient & t-value & Coefficient & t-value & Coefficient & t-value \\
\hline \multicolumn{9}{|l|}{ Control Levers } \\
\hline DIAG & 0.071 & 0.606 & 0.126 & 1.077 & 0.156 & 1.303 & 0.182 & 1.515 \\
\hline INT & 0.127 & 1.058 & 0.108 & 0.908 & 0.006 & 0.047 & 0.017 & 0.131 \\
\hline BOUND & 0.097 & 0.096 & 0.095 & 0.953 & 0.112 & 1.107 & 0.098 & 0.959 \\
\hline BELIEF & 0.221 & $2.198^{\star *}$ & 0.206 & $1.952^{*}$ & 0.173 & $1.729^{*}$ & 0.166 & 1.556 \\
\hline \multicolumn{9}{|l|}{ Interaction Terms } \\
\hline DIAG x INT & & & 0.223 & $2.398^{* *}$ & & & 0.169 & $1.735^{\star}$ \\
\hline BOUND x BELIEF & & & -0.051 & -0.525 & & & -0.059 & -0.585 \\
\hline \multicolumn{9}{|l|}{ Difference Terms } \\
\hline ABS[DIAG - INT] & & & & & -0.244 & $-2.519^{* *}$ & -0.186 & $-1.833^{*}$ \\
\hline ABS[BOUND - BELIEF] & & & & & 0.001 & 0.013 & -0.029 & -0.314 \\
\hline \multicolumn{9}{|l|}{ Firm Controls } \\
\hline AGE & -0.115 & -1.232 & -0.062 & -0.661 & -0.107 & -1.172 & -0.070 & -0.748 \\
\hline SIZE & 0.153 & $1.646^{*}$ & 0.163 & $1.785^{\star}$ & 0.165 & $1.811^{*}$ & 0.172 & $1.891^{* *}$ \\
\hline ENVHOST & 0.017 & 0.183 & 0.021 & 0.230 & 0.060 & 0.646 & 0.056 & 0.610 \\
\hline ENVDYN & -0.291 & $-3.188^{\star * *}$ & -0.274 & $-3.039^{\star \star \star}$ & -0.309 & $-3.447^{\star \star \star}$ & -0.291 & $-3.238^{\star * *}$ \\
\hline R-Sq. & \multicolumn{2}{|c|}{0.266} & \multicolumn{2}{|c|}{0.309} & \multicolumn{2}{|c|}{0.312} & \multicolumn{2}{|c|}{0.335} \\
\hline Adj. R-Sq. & \multicolumn{2}{|c|}{0.204} & \multicolumn{2}{|c|}{0.235} & \multicolumn{2}{|c|}{0.239} & \multicolumn{2}{|c|}{0.249} \\
\hline$F$-Value & \multicolumn{2}{|c|}{4.340} & \multicolumn{2}{|c|}{4.194} & \multicolumn{2}{|c|}{4.273} & \multicolumn{2}{|c|}{3.866} \\
\hline Sig. $F$ & \multicolumn{2}{|c|}{0.000} & \multicolumn{2}{|c|}{0.000} & \multicolumn{2}{|c|}{0.000} & \multicolumn{2}{|c|}{0.000} \\
\hline
\end{tabular}

PERF: subjective assessment of firm performance; DIAG: emphasis on diagnostic control systems; INT: emphasis on interactive control systems; BOUND: emphasis on boundary control systems; BELIEF: emphasis on belief control systems; ABS[DIAG-INT]: absolute difference between the emphasis on diagnostic and interactive control systems; ABS[BOUND-BELIEF]: absolute difference between the emphasis on boundary and belief control systems; AGE: dummy indicating whether the firm is at least 20 years old (1) or not (0); SIZE: natural logarithm of the number of employees in the firm; ENVHOST: degree of hostility in the firm's environment; ENVDYN: degree of dynamism in the firm's environment.

a Standardized coefficients reported.

* $p<.10$ (two-tailed).

** $\quad p<.05$ (two-tailed).

*** $\quad p<.01$ (two-tailed). 
Appendix A

Survey instrument items

\section{Diagnostic Control Systems}

To what extent does the top management team use budgets and performance measures for the following

1.1 Identify critical performance variables (i.e. factors that indicate achievement of current strategy)

1.2 Set targets for critical performance variables

1.3 Monitor progress towards critical performance targets

1.4 Provide information to correct deviations from preset performance targets

1.5 Review key areas of performance

\section{Interactive Control Systems}

To what extent does the top management team use budgets and performance measures for the following

2.1 Provide a recurring and frequent agenda for top management activities

2.2 Provide a recurring and frequent agenda for subordinate activities

2.3 Enable continual challenge and debate of underlying data, assumptions and action plans with subordinates and peers

2.4 Focus attention on strategic uncertainties (i.e. factors that may invalidate current strategy or provide opportunities for new strategic initiatives)

2.5 Encourage and facilitate dialogue and information sharing with subordinates

\section{Boundary Control Systems}

To what extent...

3.1 Are codes of conduct or similar statements relied upon to define appropriate behaviour?

3.2 Are there policies or guidelines that stipulate specific areas for, or limits on, opportunity search and experimentation?

3.3 Does top management actively communicate risks and activities to be avoided by subordinates?

3.4 Are sanctions or punishments applied to subordinates who engage in risks and activities outside organisational policy, irrespective of the outcome?

\section{Belief Control Systems}

To what extent...

4.1 Are the values, purpose and direction of the SBU codified in formal documents? (e.g. mission/value statements, credos, statements of purpose?)

4.2 Does top management actively communicate core values to subordinates?

4.3 Are formal statements of values used to create commitment to the long-term vision of top management?

4.4 Are formal statements of values used to motivate and guide subordinates in searching for new opportunities?

\section{Exploitation and Exploration}

Indicate the emphasis your SBU places on the following strategic priorities relative to your competitors

5.1 Low cost products / services *

5.2 Being first to market with new products / services

5.3 Developing new generation product / service capabilities
Very low extent / Very high extent

Very low extent / Very high extent

Very low extent / Very high extent

Very low extent / Very high extent

Very low emphasis / Very high emphasis 
5.4 Frequent new product / service introductions

5.5 Experimenting with new products / services

5.6 Improving quality of existing products / services

5.7 Frequent, but incremental, modifications to existing products / services

5.8 Improving efficiency in the provision of existing products / services

5.9 Opening up new product / service markets

5.10 Increasing economies of scale in existing product / service markets

${ }^{*}$ This item is dropped from the analysis

\section{Firm Performance}

Rate the performance of your SBU on the following dimensions to that of your competitors over the past year

6.1 Financial performance

6.2 Sales growth of new (less than 2 years) product / service markets

6.3 Sales growth of existing (older than 2 years) product / service markets

6.4 Relative market share for primary products / services

6.5 Overall performance

\section{Environmental Hostility}

7.1 How intense is the competition for your main products/services?

7.2 How difficult is it to obtain the necessary inputs for your business?

7.3 How many strategic opportunities are currently available to your business?

\section{Environmental Dynamism}

Over the past three years how predictable or unpredictable have important actions or changes in the external environment been?

Over the past three years how many changes have occurred that have had a material impact on the nature of your business?

8.1 Customers (e.g. Level of demand, customer requirements)

8.2 Suppliers (e.g. Markets for key inputs, quality of resources)

8.3 Competitors (e.g. Competitors entering or leaving, tactics/strategies)

8.4 Technological (e.g. R\&D advances, process innovations)

8.5 Economic / Regulatory
Significantly below average / Significantly above average

Very low intensity / Very high intensity Very low difficulty / Very high difficulty Very few / Very many

Very predictable / Very unpredictable

Very few changes / Very many changes 


\section{References}

Abernathy, W., Clark, K., 1985. Innovation: mapping the winds of creative destruction. Res. Policy 14, 3-22.

Abernethy, M.A., Brownell, P., 1999. The role of budgets in organisations facing strategic change: an exploratory study. Account. Org. Soc. 24 (3), 189-204.

Adler, P.S., Goldoftas, B., Levine, D.I., 1999. Flexibility versus efficiency? A case study of model changeovers in the Toyota production system. Org. Sci. 10 (1), 43-68.

Adler, P.S., Chen, C.X., 2011. Combining creativity and control: understanding individual motivation in large-scale collaborative creativity. Account. Org. Soc. 36 (1), 63-85.

Ahrens, T., Chapman, C.S., 2004. Accounting for flexibility and efficiency: a field study of management control systems in a restaurant chain. Cont. Account. Res. 21 (2), 271-301.

Amabile, T.M., 1988. A model of creativity and innovation in organizations, in: Staw, B.M., Cummings, L.L. (Eds.), Research in Organizational Behaviour. JAI Press, Greenwich, pp. 123-167.

Andriopoulos, C., Lewis, M.W., 2009. Exploitation-exploration tensions and organizational ambidexterity: managing paradoxes of innovation. Org. Sci. 20, 696-717.

Argyris, C., Schön, D.A., 1978. Organizational Learning: A Theory of Action Perspective. Addison-Wesley, Reading.

Bartlett, C.A., Ghoshal, S. 1993. Beyond the M-form: toward a managerial theory of the firm. Strat. Manage. J. 14, $23-46$.

Benner, M.J., Tushman, M.L., 2002. Process management and technological innovation: a longitudinal study of the photography and paint industries. Admin. Sci. Quart. 47, 676-706.

Benner, M.J., Tushman, M.L., 2003. Exploitation, exploration, and process management: the productivity dilemma revisited. Acad. Manage. Rev. 28, 238-56.

Bisbe, J., Otley, D., 2004. The effects of the interactive use of management control systems on product innovation. Account. Org. Soc. 29 (8), 709-737.

Bisbe, J., Batista-Foguet, H-M., Chenhall, R., 2007. Defining management accounting constructs: a methodological note on the risks of conceptual misspecification. Account. Org. Soc. 32, 789-820.

Bisbe, J., Malagueño, R., 2009. The choice of interactive control systems under different innovation management modes. Eur. Account. Rev. 18 (2), 371-405.

Boumgarden, P., Nickerson, J., Zenger, T.R., 2012. Sailing into the wind: exploring the relationships among ambidexterity, vacillation, and organizational performance. Strat. Manage. J. 33, 587-610.

Burgelman, R.A., 1991. Intraorganizational ecology of strategy making and organizational adaptation: theory and field research. Org. Sci. 2, 239-262.

Burgelman, R.A., 2002. Strategy is Destiny: How Strategy-making Shapes a Company's Future. Free Press, New York.

Cameron, K.S., 1986. Effectiveness as paradox: consensus and conflict in conceptions of organizational effectiveness. Manage. Sci. 32 (5), 539-553.

Cao, Q., Gedajlovic, E., Zhang, H., 2009. Unpacking organizational ambidexterity: dimensions, contingencies, and synergistic effects. Org. Sci. 24 (4), 781-796.

Cardinal, L.B., 2001. Technological innovation in the Pharmaceutical industry: the use of organizational control in managing research and development. Org. Sci. 12 (1), 19-36.

Cardinal, L.B., Sitkin, S.B., Long, C.P., 2004. Balancing and rebalancing in the creation and evolution of organizational control. Org. Sci. 15 (4), 411-431.

Chapman, C.S., 1997. Reflections on a contingent view of accounting. Account. Org. Soc. 22, 189-205.

Cheng, Y.T., Van de Ven, A.H., 1996. Learning the innovation journey: order out of chaos? Org. Sci. 7, 593-614.

Chenhall, R.H., 2003. Management control systems design within its organisational context: findings from contingency-based research and directions for the future. Account. Org. Soc. 28, 127-168.

Chenhall, R.H., 2004. The role of cognitive and affective conflict in early implementation of activity-based cost management. Behav. Res. Account. 16, 19-44.

Chenhall, R.H., Morris, D., 1993. The role of post completion audits, managerial learning, environmental uncertainty and performance. Beh. Res. Account. 5, 170-186.

Chenhall, R.H., Morris, D., 1995. Organic decision and communication processes and management accounting systems in entrepreneurial and conservative business organizations. Om. Int. J. Manage. Sci. 23 (5), 485-497.

Chenhall, R.H., Hall, M., Smith. D., 2010. Social capital and management control systems: a study of a nongovernment organization. Account. Org. Soc. 35, 737-756. 
Cohen, J., Cohen, P., West, S., Aiken, L., 2003. Applied Multiple Regression / Correlation Analysis for the Behavioural Sciences, third ed. L. Erlbaum Associates, New Jersey.

D’Aveni, R., 1994. Hypercompetition: Managing the Dynamics of Strategic Maneuvering. Free Press, New York.

Damanpour, F., 1991. Organizational innovation: a meta-analysis of effects of determinants and moderators. Acad. Manage. J. 34, 555-590.

Danneels, E., 2008. Organizational antecedents of second-order competencies. Strat. Manage. J. 29, 519-543.

Davila, T., 2000. An empirical study on the drivers of management control systems' design in new product development. Account. Org. Soc. 25, 383-409.

Davila, A., Foster, G., Oyon, D., 2009. Accounting and control, entrepreneurship and innovation: venturing into new research opportunities. Eur. Account. Rev. 18 (2), 281-311.

Deci, E.L., Ryan, R.M., 1985. Intrinsic motivation and self-determination in human behavior. Plenum, New York.

Dekker, H.C., Groot, T.L.C.M., Schoute, M., 2013. The implications of mixed strategies for performance measurement system design. J. Manage. Account. Res. Forthcoming.

Dess, G.G., Beard, D.W., 1984. Dimensions of organizational task environments. Admin. Sci. Quart. 29, 52-73.

Diamantopoulos, A., Winklhofer, H., 2001. Index construction with formative indicators: an alternative to scale development. J. Mark. Res. 38, 269-77.

Dillman, D.A., 2000. Mail and Internet Surveys: The Tailored Design Method. John Wiley and Sons, Canada.

Ditillo, A., 2004. Dealing with uncertainty in knowledge-intensive firms: the role of management control systems as knowledge integration mechanisms. Account. Org. Soc. 29, 401-421.

Duncan, R.B., 1976. The ambidextrous organization: designing dual structures for innovation, in: Kilmann, R.H., Pondy, L.R., Slevin, D. (Eds.), The Management of Organization, Vol. 1. North-Holland, New York, pp. 167188.

Dunk, A.S., 1992. Reliance on budgeting control, manufacturing process automation and production subunit performance: a research note. Account. Org. Soc. 17, 195-203.

Eisenhardt, K.M., 2000. Paradox, spirals, ambivalence: the new language of change and pluralism. Acad. Manage. Rev. 25 (4), 703-705.

Eisenhardt, K.M., Furr, N.R., Bingham, C.B., 2010. Microfoundations of performance: balancing efficiency and flexibility in dynamic environments. Org. Sci. 21 (6), 1263-1273.

Everitt, B., Landau, S., Leese, M., 2001. Cluster Analysis, fourth ed. Arnold, Great Britain.

Fama, E.F., French, K.R., 1995. Size and book to market factors in earnings and returns. J. Fin. 50, 131-155.

Frow, N., Marginson, D., Ogden, S., 2010. "Continuous" budgeting: reconciling budget flexibility with budgetary control. Account. Org. Soc. 35, 444-461.

Galbraith, J., 1973. Designing Complex Organisations. Addison Wesley Publishing, United States.

Gerdin, J., Greve, J., 2008. The appropriateness of statistical methods for testing contingency hypotheses in management accounting research. Account. Org. Soc. 33, 995-1009.

Gibson, C.B., Birkinshaw, J., 2004. The antecedents, consequences, and mediating role of organizational ambidexterity. Acad. Manage. J. 47 (2), 209-226.

Gooding, R.Z., Wagner III, J.A., 1985. A meta-analytic review of the relationship between size and performance: the productivity and efficiency of organizations and their subunits. Admin. Sci. Quart. 30, 462-481.

Gordon, L.A., Narayanan, V.K.., 1984. Management accounting systems, perceived environmental uncertainty and organization structure: an empirical investigation. Account. Org. Soc. 9 (1), 33-47.

Gresov, C., Drazin, R., 1997. Equifinality: Functional equivalence in organization design. Acad. Manage. Rev. 22 (2), 403-428.

Gupta, A.K., Govindarajan, V., 1986. Resource sharing among SBUs: strategic antecedents and administrative implications. Acad. Manage. J. 29, 695-714.

Gupta, A.K., Smith, K.G., Shalley, C.E., 2006. The interplay between exploration and exploitation. Acad. Manage. J. 49, 693-706.

Hair, J., Anderson, R., Tatham, R., Black, W., 2006. Multivariate Data Analysis, sixth ed. Prentice Hall, New Jersey.

Hall, M., 2010. Accounting information and managerial work. Account. Org. Soc. 35, 301-315.

Hannan, M.T., Freeman, J., 1989. Organizational Ecology. Harvard University Press, Cambridge.

Hansen, M.T., 2002. Knowledge networks: explaining effective knowledge sharing in multiunit companies. Org. Sci. 13, 232-248.

He, Z-L., Wong, P-K., 2004. Exploration vs. exploitation: an empirical test of the ambidexterity hypothesis. Org. Sci. 15 (4), 481-494. 
Henri, J-F., 2006. Management control systems and strategy: a resource-based perspective. Account. Org. Soc. 31 (6), 529-558.

Holmqvist, M., 2004. Experiential learning process of exploitation and exploration within and between organizations: an empirical study of product development. Org. Sci. 15, 70-81.

Jansen, J.J.P., Van den Bosch, F.A.J., Volberda, H.W., 2006. Exploratory innovation, exploitative innovation, and performance: effects of organizational antecedents and environmental moderators. Manage. Sci. 52 (11), 16611674.

Jansen, J., George, G., Van den Bosch, F.A.J., Volberda, H.W., 2008. Senior team attributes and organizational ambidexterity: the moderating role of transformational leadership. J. Manage. Stud. 45, 982-1007.

Jansen, J.J.P., Tempelaar, M.P., Van den Bosch, F.A.J., Volberda, H.W., 2009. Structural differentiation and ambidexterity: the mediating role of integration mechanisms. Org. Sci. 20 (4), 797-811.

Jarvis, C.B., MacKenzie, S.B., Podsakoff, P.M., 2003. A critical review of construct indicators and measurement model misspecification in marketing and consumer research. J. Con. Res. 30, 199-218.

Jørgensen, B., Messner, M., 2009. Management control in new product development: the dynamics of managing flexibility and efficiency. J. Manage. Account. Res. 21, 99-124.

Kanter, R. M., 2006. Innovation: The classic traps. Har. Bus. Rev. November, 73-83.

Ketchen, D.J.Jr., Shook, C.L., 1996. The application of cluster analysis in strategic management research: an analysis and critique. Strat. Manage. J. 17, 441-458.

Leonard-Barton, D., 1992. Core capabilities and core rigidities: a paradox in managing new product development. Strat. Manage. J. 13, 111-126.

Levinthal, D.A., 1997. Adaptation on rugged landscapes. Manage. Sci. 43, 377-415.

Levinthal, D.A., March, J.G., 1993. The myopia of learning. Strat. Manage. J. 14, 95-112.

Lewis, M.W., 2000. Exploring paradox: toward a more comprehensive guide. Acad. Manage. Rev. 25 (4), 760-776.

Lillis A.M., van Veen-Dirks, P.M.G., 2008. Performance measurement system design in joint strategy settings. J. Manage. Account. Res. 20, 25-57.

Lubatkin, M.H., Simsek, Z., Ling, Y., Veiga, J.F., 2006. Ambidexterity and performance in small- to medium-sized firms: the pivotal role of top management team behavioral integration. J. Manage. 32, 646-72.

March, J.G., 1973. The technology of foolishness. In Levitt, H.J., Pondy L.R. (Eds.), Readings in Managerial Psychology, second ed. University of Chicago Press, Chicago.

March, J.G., 1991. Exploration and exploitation in organizational learning. Org. Sci. (2), 71-87.

Marginson, D.E.W., 2002. Management control systems and their effects on strategy formation at middlemanagement levels: evidence from a U.K. organization. Strat. Manage. J. 23, 1019-1031.

McGrath, R.G., 2001. Exploratory learning, innovative capacity and managerial oversight. Acad. Manage. J. 44, $118-131$.

Milgrom, P., Roberts, J., 1995. Complementarities and fit strategy, structure, and organizational change in manufacturing. J. Account. Econ. 19 (2-3), 179-208.

Miller, D., Friesen, P.H., 1983. Strategy-making and environment: the third link. Strat. Manage. J. 4, 221-235.

Miller, D., Friesen, P. H., 1984. Organizations - A Quantum View. Prentice-Hall, New Jersey.

Mundy, J., 2010. Creating dynamic tensions through a balanced use of management control systems. Account. Org. Soc. 35, 499-523.

Naranjo-Gil, D., Hartmann, F., 2007. Management accounting systems, top management team heterogeneity and strategic change. Account. Org. Soc. 28 (7-8), 735-756.

O’Reilly, C.A., Tushman, M.L., 2008. Ambidexterity as a dynamic capability: resolving the innovator's dilemma. Res. Org. Beh. 28, 185-206.

Osborn, C.S., 1998. Systems for sustainable organizations: emergent strategies, interactive controls and semi-formal information. J. Manage. Stud. 35 (4), 481-509.

Ouchi, W., 1979. A conceptual framework for the design of organizational control mechanisms. Manage. Sci. 25 (9), 833-848.

Pearce II, J.A., 1982. The company mission as a strategic tool. Sloan Manage. Rev. Spring, 15-24.

Petter, S., Straub, D., Rai, A., 2007. Specifying formative constructs in information systems research. MIS Quart. 31, 623-656.

Podsakoff, P., Organ, D.W., 1986. Self-reports in organizational research: problems and prospects. J. Manage. 12, 531-544.

Raisch, S., Birkinshaw, J., 2008. Organizational ambidexterity: antecedents, outcomes, and moderators. J. Manage. 34, 375-408. 
Raisch, S., Birkinshaw, J., Probst, G., Tushman, M.L., 2009. Organizational ambidexterity: Balancing exploitation and exploration for sustained performance. Org. Sci. 20 (4), 685-695.

Rodan, S., 2005. Exploration and exploitation revisited: extending March's model of mutual learning. Scand. J. Manage. 21, 407-428.

Rossiter, J.R., 2002. The C-O-A-R-SE procedure for scale development in marketing. Int. J. Res. Mark. 19, 305335.

Sandino, T., 2007. Introducing the first management control systems: evidence from the retail sector. Account. Rev. $82(1), 265-293$.

Schreyogg, G., Sydow, J., 2010. Organizing for fluidity? Dilemmas of new organizational forms. Org. Sci. 21 (6), $1251-1262$.

Selto, F., Renner, C., Young, S., 1995. Assessing the organisational fit of a just-in-time manufacturing system: testing selection, interaction and systems models of contingency theory. Account. Org. Soc. 20, 665-684.

Siggelkow, N., 2002. Misperceiving interactions among complements and substitutes: Organizational consequences. Manage. Sci. 48(7), 900-916.

Simons, R., 1994. How new top managers use control systems as levers of strategic renewal. Strat. Manage. J. 15, 169-189.

Simons, R., 1995. Levers of Control. Harvard University Press, Boston.

Simons, R., 2000. Performance Measurement and Control Systems for Implementing Strategy. Prentice Hall, Upper Saddle River.

Simons, R., 2010. Seven Strategy Questions: A Simple Approach for Better Execution. Harvard Business Review Press, Boston.

Simsek, Z., 2009. Organizational ambidexterity: towards a multilevel understanding. J. Manage. Stud. 46 (4), $597-$ 624.

Smith, W., Tushman, M., 2005. Managing strategic contradictions: a top management model for managing innovation streams. Org. Sci. 16, 522-36.

Smith, W.K., Lewis, M.W., 2011. Toward a theory of paradox: a dynamic equilibrium model of organizing. Acad. Manage. Rev. 36 (2), 381-403.

Sorensen, J., 2002. The strength of corporate culture and the reliability of firm performance. Admin. Sci. Quart. 47, $70-91$.

Speklé, R., 2001. Explaining management control structure variety: a transaction cost economics perspective. Account. Org. Soc. 26, 419-441.

Tan, J.J., Litschert, R.J., 1994. Environment-strategy relationship and its performance implications: an empirical study of the Chinese electronics industry. Strat. Manage. J. 15, 1-20.

Tuomela, T-S., 2005. The interplay of different levers of control: a case study of introducing a new performance measurement system. Manage. Account. Res. 16, 293-320.

Turner, K.L., Makhija, M.V., 2006. The role of organizational controls in managing knowledge. Acad. Manage. Rev. 31 (1), 197-217.

Tushman, M.L., O’Reilly III, C.A., 1996. Ambidextrous organizations: managing evolutionary and revolutionary change. Cal. Manage. Rev. 38, 8-30.

Van de Ven, A.H., 1986. Central problems in the management of innovation. Manage. Sci. 32 (5), 590-607.

Venkatraman, N., Ramanujam, V. 1987. Measurement of business economic performance: an examination of method convergence. J. Manage. 13 (1), 109-122.

Weick, K.E., 1979. The social psychology of organizing, second ed. Addison-Wesley, Reading.

Widener, S.K., 2007. An empirical analysis of the levers of control framework. Account. Org. Soc. 32 (7-8), 757788.

Ylinen, M., Gullkvist, B., 2012. The effects of tolerance for ambiguity and task uncertainty on the balanced and combined use of project controls. Eur. Account. Rev. 21 (2), 395-415.

Zahra, S.A., 1996. Governance, ownership, and corporate entrepreneurship: the moderating impact of industry technological opportunities. Acad. Manage. J. 39 (6), 1713-1735. 